\title{
Structure, Temperature Effect and Bonding Order Analysisof Hydrated Bromide Clusters
}

Hui Wen, ${ }^{1}$ Teng Huang, ${ }^{1}$ Yi-Rong Liu, ${ }^{1}$ Shuai Jiang, ${ }^{1}$ Xiu-Qiu Peng, ${ }^{1}$ Shou-Kui Miao, ${ }^{1}$ Chun-Yu Wang, ${ }^{1}$ Yu Hong, ${ }^{1}$ Wei Huang ${ }^{1,2,3, *}$

${ }^{1}$ Laboratory of Atmospheric Physico-Chemistry, Anhui Institute of Optics \& Fine Mechanics, Chinese Academy of Sciences, Hefei, Anhui 230031, China

${ }^{2}$ School of Environmental Science \& Optoelectronic Technology, University of Science and Technology of China, Hefei, Anhui 230026, China

${ }^{3}$ Center for Excellence in Urban Atmospheric Environment, Institute of Urban Environment, Chinese Academy of Sciences, Xiamen, Fujian 361021, China

*Corresponding Author: Huangwei6@ustc.edu.cn

\begin{abstract}
Halide ions have been received intense interest in charactering and understanding their implications in atmospheric chemistry since they are related to the ozone destruction in the stratosphere. In the current study, structures, thermodynamic properties, and spectroscopic signatures of hydrated bromide $\operatorname{Br}^{-}\left(\mathrm{H}_{2} \mathrm{O}\right)_{n} \quad(n=1-8)$ clusters are thoroughly studied and compared with available studies, the new global minima were observed for the larger size $\mathrm{Br}^{-}\left(\mathrm{H}_{2} \mathrm{O}\right)_{7,8}$ clusters. The numbers of isomer increase with the increasing water molecules, considering the growing complexity, the isomer populations of each size clusters are provided under a wide temperature range, it was shown that different type of structures possess different temperature dependences. In addition, the bond order of different bond types of hydrated bromide has been systematically investigated for the first time.
\end{abstract}

Keywords: hydrated halide, bond order, temperature effect, basin-hopping 


\section{INTRODUCTION}

Halide-water cluster plays an important role in cluster science because of their unique spectroscopic and thermodynamic properties. In addition, they are also related to the catalytic reactions of ozone destruction in the atmosphere. These characteristics render them a useful simplified model to study the macro phenomenon, from the point of view of size, geometry, charge density, and spectroscopic details on chemical dynamics. $^{1,2}$

The structure and reactivity of water molecules with singly charged halide ions have been extensively investigated by both experiment and theory. Experimentally, size-selected halide ion-water complexes were first studied using high pressure mass spectrometry $^{3,4}$ and photoelectron spectroscopy. ${ }^{5,6}$ More recently, infrared ${ }^{7-9}$ and ZEKE $^{10,11}$ spectroscopies have been applied to probe the structures and kinetics of anionic halide-water clusters and their corresponding neutral counterparts. In particular, the Johnson group conducted extensive experimental work on a halide ion-water clusters via vibrational spectra and provided abundant spectroscopic data that yielded critical structural information. ${ }^{1,7,12-21}$

Computer simulations can help to provide essential insight into the structures and dynamics of solvation shells around ions since the experimental determination is generally difficult. The abundance of experimental data on $\mathrm{X}^{-}\left(\mathrm{H}_{2} \mathrm{O}\right)_{\mathrm{n}},(\mathrm{X}=\mathrm{F}, \mathrm{Cl}, \mathrm{Br}$, and I) clusters, ${ }^{1,7,12-21}$ motivated the theoreticians to use different methods, ranging from the empirically constructed potential energy surfaces ${ }^{22-24}$ to quantum chemistry calculations, ${ }^{25-37}$ to explain the experimental findings.

In general, the potential energy surface of the hydrated molecular clusters supports a large number of minima, and the task of finding the lowest one is difficult and tedious. The minima are obtained through manual search in many studies. However, this method is less reliable for the large molecular systems with multiple local minima, which has motivated researchers to use various global optimization techniques to seek the local minima. 
Neogi et al. evaluated the structures of halide-water clusters by stochastic search-based genetic algorithm in conjunction with density functional theory (GA-DFT) method. ${ }^{25}$ Head-Gordon and coworkers ${ }^{28}$ studied the effect of charge transfer of $\mathrm{Cl}-\mathrm{H}_{2} \mathrm{O}$ dimers using the absolutely localized molecular orbital (ALMO) model. Jahangiri et al. described the interatomic interactions of halide hydration via self-consistent charge density functional tight binding (DFTB) method. ${ }^{33}$ Kim et al. adopted time-dependent density-functional theory (TDDFT) to obtained the absorption maxima of $\mathrm{Br}^{-}\left(\mathrm{H}_{2} \mathrm{O}\right)_{n}$ clusters for the transitions from the ground states to the first excited states. ${ }^{29,31,32}$ Recently, Jiang utilized the Basin-Hopping algorithm together with DFT (BH-DFT) to study the structures and energetics of $\mathrm{Br}^{-}\left(\mathrm{H}_{2} \mathrm{O}\right)_{\mathrm{n}}$ clusters. ${ }^{26,27}$ All of these methods are effective for investigating the halide hydrated clusters and these works indeed provide a comprehensive probe for the micro solvation of halide ion. However, the detailed bonding order investigations are rarely report since the interactions present in the clusters are coupling effects, which may lead to many interesting properties.

In the current work, modified BH-DFT method (a new compressed sampling skill was introduced ${ }^{42}$ ) has been employed to study the properties of hydrated bromide clusters and extent to the larger size, additionally, for the first time, temperature effect of different isomers with same size are studied at a relatively wide temperature range (50-450 K), the bond order of both the hydrogen bonds and hydrogen-halogen interactions of hydrated bromide clusters are also determined.

\section{METHODOLOGY}

The BH algorithm was employed to search the hydrated bromide cluster structures. This method has been successfully adopted to explore the structures of atomic clusters. ${ }^{38-41}$ Recently, a new compressed sampling ${ }^{42}$ was introduced in the $\mathrm{BH}$ code, ${ }^{42}$ we performed an extensive search for the potential energy surface of $\mathrm{Br}^{-}\left(\mathrm{H}_{2} \mathrm{O}\right)_{\mathrm{n}}(\mathrm{n}=1-8)$ clusters using the modified $\mathrm{BH}$ algorithm.

The gradient-corrected Perdew-Burke-Ernzerhof $(\mathrm{PBE})^{43}$ exchange correlation 
functional together with the double numerical polarized (DNP) basis set with effective core potentials (ECPs) is used to generate the isomer populations, as implemented in the $\mathrm{DMol}^{3}$ code $^{44}$ with a medium level convergence criterion.

Hundreds of structures were searched for each size of clusters. All of the isomers for each size cluster were ranked according to their relative energies; top twenty isomers in each species were picked and first optimized at the B3LYP/aug-cc-pVDZ level. The stable isomers from the first optimization were then selected and further optimized by the B3LYP/aug-cc-pVTZ level of theory ${ }^{45}$ to get the final configurations. Harmonic vibrational frequencies were calculated to confirm that the obtained isomers are the true minima.

Single-point energy (SPE) calculations were performed at relatively higher theory, MP2/aug-cc-pVDZ. Theoretical vertical detachment energy (VDE) for each species was calculated as the energy difference between the anion and neutral at the optimized anion's configuration. The zero-point energy correction (ZPE) was calculated at $0 \mathrm{~K}$, the thermodynamic parameters were obtained at 1 atmosphere and $298.15 \mathrm{~K}$. All calculations were implemented in the Gaussian 09 package. ${ }^{46}$ The bond order calculations were performed at B3LYP/cc-pVDZ, B3LYP/cc-pVTZ levels, and their augmented with diffusion functions: B3LYP/aug-cc-pVDZ and B3LYP/aug-cc-pVTZ levels, as implemented in the Multiwfn code. ${ }^{47}$

\section{THEORETICAL RESULTS}

Our BH-based searching method generated numerous local minima for $\mathrm{Br}^{-}\left(\mathrm{H}_{2} \mathrm{O}\right)_{n}$ $(n=1-8)$ clusters. The optimized low-lying structures together with their relative energies (within $5 \mathrm{kcal} \mathrm{mol}^{-1}$, without ZPE correction) are presented in Figs. 1-3 and $\mathrm{S} 2$. The global minima of the pure water clusters $\left(\mathrm{H}_{2} \mathrm{O}\right)_{1-9}$ are depicted for comparison in Fig. S1. All of the geometries were verified by the harmonic frequency calculations at the B3LYP/aug-cc-pVTZ level of theory. An overview of all the structures suggested that the $\mathrm{Br}^{-}\left(\mathrm{H}_{2} \mathrm{O}\right)_{\mathrm{n}}(\mathrm{n}=1-8)$ clusters prefer surface solvation. 
$\mathbf{B r}^{-}\left(\mathbf{H}_{2} \mathrm{O}\right)_{1}$. The only structure obtained for $\mathrm{Br}^{-}\left(\mathrm{H}_{2} \mathrm{O}\right)_{1}$ possesses an asymmetric structure ( $C_{s}$ symmetry), where one $\mathrm{H}$ is attached to the $\mathrm{Br}^{-}$ion and the other remains free, forming an ionic hydrogen bond $\mathrm{O}-\mathrm{H}^{\cdots} \mathrm{Br}^{-}$(hydrogen-halogen interaction). The structure is consistent with that obtained by previous study. ${ }^{34,36}$

$\mathbf{B r}^{-}\left(\mathbf{H}_{2} \mathbf{O}\right)_{2}$. The minimum energy isomer possesses $C_{1}$ symmetry, which is yielded two $\mathrm{O}-\mathrm{H}^{\cdots} \cdot \mathrm{Br}^{-}$weak interactions. The two $\mathrm{O}-\mathrm{H}^{-} \cdot \mathrm{Br}^{-}$interactions are not of equal strength, $2.63 \AA$ and $2.34 \AA$, respectively. Two water molecules are attached with an $\mathrm{O}-\mathrm{H} \cdots \mathrm{O}$ hydrogen bond, which is much smaller $(2.16 \AA)$ than the $\mathrm{O}-\mathrm{H}^{\cdots} \cdot \mathrm{Br}^{-}$ interaction. The structure can be viewed as a triangle shape, which is similar to the previous work ${ }^{34,36}$ as well as the water trimer (Fig. S1).

$\mathbf{B r}^{-}\left(\mathbf{H}_{2} \mathrm{O}\right)_{3}$. The minimum energy isomer of the $\operatorname{Br}^{-}\left(\mathrm{H}_{2} \mathrm{O}\right)_{3}$ cluster adopts a $C_{3}$ pyramidal structure, with a ring formed by three water molecules. The ring forms the base of a trigonal pyramid with the $\mathrm{Br}^{-}$ion at its peak. A significant structural difference is found between the global minima and the competing local minimum (III b), which possesses planar $C_{s}$ symmetry, similar to the water tetramer in Fig. S1. The second-hydration-shell structures (III b and III c) appear in this system.

$\mathrm{Br}^{-}\left(\mathrm{H}_{2} \mathrm{O}\right)_{4}$. The lowest energy isomer of $\mathrm{Br}^{-}\left(\mathrm{H}_{2} \mathrm{O}\right)_{4}$ cluster has a pyramidal $\left(C_{4}\right)$ configuration, where the $\mathrm{Br}^{-}$ion sits at the apex of pyramid with the four water monomers arranged so that each has two hydrogen bonds with neighboring water molecules and one ionic hydrogen bond to the $\mathrm{Br}^{-}$ion. All four water molecules involved in $\mathrm{O}-\mathrm{H} \cdots \mathrm{O}$ interactions, giving the structure its stability. The $\mathrm{Br}^{-}\left(\mathrm{H}_{2} \mathrm{O}\right)_{4}$ cluster favors the 3D configuration, which is inconsistent with the pure water pentamer (planar pentagon) in Fig. S1.

$\mathbf{B r}^{-}\left(\mathbf{H}_{2} \mathbf{O}\right)$ 5. The structure of the minimum energy isomer has four water molecules disposed nearer to the $\mathrm{Br}^{-}$ion $\left(\mathrm{Br}^{-}\left(\mathrm{H}_{2} \mathrm{O}\right)_{4}\right.$ motif) and one far from it. The addition water molecule is involved in one $\mathrm{O}-\mathrm{H} \cdots \mathrm{O}$ and one $\mathrm{O}-\mathrm{H}^{\cdots} \cdot \mathrm{Br}^{-}$interaction. Our predicted minimum energy isomer is in good agreement with the results obtained 
by Kim et al. ${ }^{31}$ In addition, the minimum structure proposed by Gora ${ }^{36}$ and Masamura $^{34}$ is similar to the isomer $\mathrm{V}-\mathrm{n}$, which is $4.673 \mathrm{kcal} \mathrm{mol}^{-1}$ higher in energy in our study. The isomer V-b, which is almost isoenergetic to the minimum one, changes the orientation of hydrogen bond. Isomer V-c is similar to the minimum energy isomer of the water pentamer, but the apex is a $\mathrm{Br}^{-}$ion instead of a water monomer. A secondary hydration shell formed for most of the low-lying isomers.

$\mathbf{B r}^{-}\left(\mathbf{H}_{2} \mathbf{O}\right)_{6}$. For the global minimum, all of the water molecules are located at the same position; the two water tetramers are formed and share two water molecules. The overall structure is a cradle shape involving five $\mathrm{O}-\mathrm{H}^{\cdots} \mathrm{Br}^{-}$as well as seven $\mathrm{O}-\mathrm{H} \cdots \mathrm{O}$ interactions. This result is in agreement with that obtained by Kim et al. ${ }^{29,31,32}$ The isomer shows one water molecule located in the secondary-hydration-shell. Additionally, isomer VI-l is similar to the pure $\left(\mathrm{H}_{2} \mathrm{O}\right)_{7}$ cluster, as shown in Fig. S1.

$\mathbf{B r}^{-}\left(\mathbf{H}_{2} \mathrm{O}\right)_{7}$. Isomer VII-a is similar to the global minimum of water cubic $\left(\mathrm{H}_{2} \mathrm{O}\right)_{8}$, but one apex is replaced by $\mathrm{a} \mathrm{Br}^{-}$ion. This structure is also in agreement with the cubic shape of $\mathrm{F}^{-}\left(\mathrm{H}_{2} \mathrm{O}\right)_{7}$ and $\mathrm{Cl}^{-}\left(\mathrm{H}_{2} \mathrm{O}\right)_{7}$, recently reported by Matsuzawa et al. ${ }^{48}$ The relative energy of the following competitive isomer VII-b is less than $1 \mathrm{kcal} \mathrm{mol}^{-1}$. The majority of structures favor surface solvation, except the isomers VII-g, VII-h, VII-j, and VII-k. These isomers are higher in energy $\left(4 \mathrm{kcal} \mathrm{mol}^{-1}\right)$ than the minimum energy structure. The minimum energy cubic shape structure of $\mathrm{Br}^{-}\left(\mathrm{H}_{2} \mathrm{O}\right)_{7}$ is different from previous result, ${ }^{49}$ which has two sub-clusters composed from the water trimer and tetramer. However, the energy of the similar isomer (VII-t) is much high than the cubic shape isomer.

$\mathbf{B r}^{-}\left(\mathbf{H}_{2} \mathbf{O}\right)_{8}$. The minimum energy isomer is similar to that of $\operatorname{Br}^{-}\left(\mathrm{H}_{2} \mathrm{O}\right)_{6}$, where eight water molecules are located at the same position; the two water cubes share two water molecules in common. Ayala et al. predicted that the structure of $\mathrm{Br}^{-}\left(\mathrm{H}_{2} \mathrm{O}\right)_{8}$ cluster is formed by two water sub-clusters of four units with the $\mathrm{Br}^{-}$ion in the middle. ${ }^{49}$ However, this isomer is less stable (VIII s, $3.56 \mathrm{kcal} \mathrm{mol}^{-1}$ ) in our study. In 
addition, the relative energy of the isomer VIII b is $0.29 \mathrm{kcal} \mathrm{mol}^{-1}$ differences to the lowest one, implies that the energy difference on the potential energy surface is decreasing.

\section{Discussion}

\section{A. Structures: Surface $(S)$ vs Interior $(I)$}

According to conformation of the water molecules near the anion, two general types of configuration are produced. One is the surface $(S)$ type, which is corresponds to the $\mathrm{Br}^{-}$ion located on top of the water molecules, and the other one is interior $(I)$ type, where the water molecules surround the anion. The optimized clusters both for $S$ and $I$ types of $\mathrm{Br}^{-}\left(\mathrm{H}_{2} \mathrm{O}\right)_{\mathrm{n}}, \mathrm{n}=1-8$ are shown in Figs. 1-3, and Fig. S4. Most of the minimum energy isomers of each size are classified as $S$ type.

During the searching process, two isomers (cyclic shape, $C_{l}$ and linear structural, $\left.C_{2 h}\right)$ are found for $\mathrm{Br}^{-}\left(\mathrm{H}_{2} \mathrm{O}\right)_{2}$ clusters, which can be viewed as the precursors of the $S$ and I type configurations, respectively. However, no stable $I$ type geometry for $\mathrm{Br}^{-}\left(\mathrm{H}_{2} \mathrm{O}\right)_{2}$ because of the linear structural isomer (transition state, TS) was a saddle point on the potential energy surface, as shown in Fig.S4. For $\mathrm{Br}^{-}\left(\mathrm{H}_{2} \mathrm{O}\right)_{3}$, the $I$ type structure was stable under currently employed smaller basis set B3LYP/aug-cc-pVDZ level of theory, whereas the isomer converges to the $S$ type when performing further optimization under B3LYP/aug-cc-pVTZ level.

For both the $\mathrm{Br}^{-}\left(\mathrm{H}_{2} \mathrm{O}\right)_{4}$ and $\mathrm{Br}^{-}\left(\mathrm{H}_{2} \mathrm{O}\right)_{5}$ clusters, the $S$ type isomer corresponds to a pyramidal configuration of $n$ water molecules, whereas the $I$ type corresponds to the configuration with a pyramid formed by $n-1$ water molecules on one side of $\mathrm{Br}^{-}$and a single water monomer on its other side. Moreover, for the $\operatorname{Br}^{-}\left(\mathrm{H}_{2} \mathrm{O}\right)_{5}$ cluster, there is another I type configuration (V-o) presented in Figs. 1 and S4, where the water trimer and water dimer are separated by the $\mathrm{Br}^{-}$ion.

For $\mathrm{Br}^{-}\left(\mathrm{H}_{2} \mathrm{O}\right)_{6}$, there are many configurations for the $S$ type geometry, the cradle shaped pyramid is considered to be the global minimum, which contains three water 
molecules interacting more strongly with the $\mathrm{Br}^{-}$than the other three. The $I$ configuration is characterized by two separate sub-clusters, each consisting of three water molecules, with the $\mathrm{Br}^{-}$ion sitting in the middle, and the $\mathrm{Br}^{-}-\mathrm{H}_{2} \mathrm{O}$ distance shortened relative to the $S$ geometry. For the cluster of $\mathrm{Br}^{-}\left(\mathrm{H}_{2} \mathrm{O}\right)_{7}$, the minimum energy isomer possesses cubic shape, which can be viewed as the $S$ type geometry, only one $I$ type geometry was found. Similarly results were observed for the $\operatorname{Br}^{-}\left(\mathrm{H}_{2} \mathrm{O}\right)_{8}$ cluster. For almost all of the $I$ type geometries of each size of clusters, especially for the larger size clusters, the sub-clusters contain three or four water molecules are more stable.

In general, the structural transition from $S$ type to $I$ type can be detected by breaking one of the hydrogen bonds in the hydration network and replacing it with a stronger halogen-hydrogen bond. Comparison of the two types of geometries, the $S$ type configuration is more compact to that of $I$ type, and the $\mathrm{Br}^{-}-\mathrm{O}$ distance decreases with increasing cluster size, whereas the distance increases for the interior type configuration. In addition, considering the stability of the structures, $S$ type configurations are energetically more stable, whereas the interior type was found to have lower vibrational frequencies.

Compared to our recently study on $\mathrm{Cl}^{-}\left(\mathrm{H}_{2} \mathrm{O}\right)_{n}$ species, ${ }^{26,27}$ the structures of the various $\mathrm{Br}^{-}\left(\mathrm{H}_{2} \mathrm{O}\right)_{\mathrm{n}}$ isomers are almost similar to those of the corresponding $\mathrm{Cl}^{-}\left(\mathrm{H}_{2} \mathrm{O}\right)_{\mathrm{n}}$ isomers for $n=1-4$. However, for $n=5,6$, the configuration of low-lying isomers of $\mathrm{Br}^{-}\left(\mathrm{H}_{2} \mathrm{O}\right)_{\mathrm{n}}$ are somewhat different from that of $\mathrm{Cl}^{-}\left(\mathrm{H}_{2} \mathrm{O}\right)_{\mathrm{n}} . \mathrm{X}^{-}\left(\mathrm{H}_{2} \mathrm{O}\right)_{\mathrm{n}}[\mathrm{X}=\mathrm{F}$ to I] have been thoroughly studied using high level $a b$ initio calculations by Kim and coworkers. ${ }^{29-32}$ These systematic works have compared the structures of the different halide-water clusters and found a distinctive difference between $\mathrm{F}^{-}\left(\mathrm{H}_{2} \mathrm{O}\right)_{n}$ clusters and $\mathrm{X}^{-}\left(\mathrm{H}_{2} \mathrm{O}\right)_{\mathrm{n}},(\mathrm{X}=\mathrm{Cl}$ to $\mathrm{I})$. The minimum energy clusters of $\mathrm{Cl}^{-}\left(\mathrm{H}_{2} \mathrm{O}\right)_{\mathrm{n}}, \mathrm{Br}^{-}\left(\mathrm{H}_{2} \mathrm{O}\right)_{\mathrm{n}}$, and $\mathrm{I}^{-}\left(\mathrm{H}_{2} \mathrm{O}\right)_{n}$ show similar symmetry and tend to have surface type structures with strong hydrogen bonds between water molecules. Whereas for the $\mathrm{F}^{-}\left(\mathrm{H}_{2} \mathrm{O}\right)_{n}$ clusters, the minimum energy isomer of each size tends to favor the interior type configuration 
with strong interactions between $\mathrm{F}^{-}$and water but with negligible interaction between water molecules. The abnormal phenomenon observed in hydrated fluoride ion may be attributed to its small radius and high electronegativity. Among the halides, fluorine has the smallest atomic radius and highest electronegativity. Thus, the interaction between the fluoride ion and water molecules is strongest when compared to the same for other halides $(\mathrm{Cl}, \mathrm{Br}, \mathrm{I})$. As the electronegativity decreases and the atomic radius increases from $\mathrm{Cl}$ to $\mathrm{I}$, the hydrogen bonding interaction between these halide ions and water molecules gradually decreases, while the interaction solely between the water molecules gets stronger. As a consequence, their halide clusters tend to have surface type configuration.

\section{B. Thermodynamics: Stepwise bromide hydration}

The calculated $0 \mathrm{~K}$ binding energies with zero point energy (ZPE) correction $\left(\Delta \mathrm{E}_{\mathrm{e}}{ }^{0 \mathrm{~K}}\right)$, binding energies without ZPE correction $\left(\Delta \mathrm{E}_{0}{ }^{0 \mathrm{~K}}\right)$, and the calculated 298.15 $\mathrm{K}$ thermodynamic parameters, including Gibbs free energy $\left(\Delta \mathrm{G}^{298.15 \mathrm{~K}}\right)$, enthalpies $\left(\Delta \mathrm{H}^{298.15 \mathrm{~K}}\right)$, thermal energies $\left(\Delta \mathrm{U}^{298.15 \mathrm{~K}}\right)$, and entropies $\left(\Delta \mathrm{S}^{298.15 \mathrm{~K}}\right)$, for isomers of $\mathrm{Br}^{-}\left(\mathrm{H}_{2} \mathrm{O}\right)_{1-8}$ clusters are given in Tables 1-3. The binding energies are calculated using the following equation:

$$
\Delta E_{n}=E_{n}-n \times E_{H_{2} O}-E_{B r^{-}}
$$

All of the thermodynamic parameters are calculated in a similar way. In addition to the minimum energy structures, the values of the top low-lying isomers are also presented. Furthermore, the experimentally determined Gibbs free energy $\left(\Delta \mathrm{G}_{\exp }\right)$ and the enthalpies $\left(\Delta \mathrm{H}_{\text {exp }}\right)$ of $\mathrm{Br}^{-}\left(\mathrm{H}_{2} \mathrm{O}\right)_{1-4}$ clusters are also included in Table 1 for direct comparison.

Overall, the calculated thermodynamic values are consistent with the experimental values. ${ }^{3,50}$ Compared to the $\Delta \mathrm{H}$, there is less agreement between the theoretical $\Delta \mathrm{G}$ and experimental values. In particular, the extent of agreement with the experimental values is decreases with increasing water molecules.

As shown in Tables 1-3, the thermodynamic parameters decrease monotonously 
with the increasing water clusters. The relative binding energy is in negative value, implies that the stepwise $\mathrm{Br}^{-}$ion hydration is an exothermic reaction. The trends in stepwise enthalpies $(\Delta \mathrm{H})$ can be inferred by considering the number of newly formed hydrogen bonds at each hydration step. In the current study, from $\mathrm{Br}^{-}\left(\mathrm{H}_{2} \mathrm{O}\right)_{1}$ to $\mathrm{Br}^{-}\left(\mathrm{H}_{2} \mathrm{O}\right)_{8}$ cluster, the numbers of newly formed hydrogen bonds for the minimum energy isomer ( $S$ type) are given the sequence of 1, 2, 3, 2, 1, 3, 0, and 3. A pretty stable structure is formed at $\mathrm{Br}^{-}\left(\mathrm{H}_{2} \mathrm{O}\right)_{7}$ (compact cubic shape). Compared to the $\mathrm{Br}^{-}\left(\mathrm{H}_{2} \mathrm{O}\right)_{6}$ cluster, no new hydrogen bonds are formed. Meanwhile, the magnitudes of the $\Delta \mathrm{H}$ changes at $\mathrm{Br}^{-}\left(\mathrm{H}_{2} \mathrm{O}\right)_{7}$ are also greater than the previous step, as shown in Tables 2 and 3. This extra stabilization is due to the construction of a cubic-shape structure with only three water monomers connected to the $\mathrm{Br}^{-}$, whereas four water monomers bound to the $\mathrm{Br}^{-}$ion observed at $\mathrm{Br}^{-}\left(\mathrm{H}_{2} \mathrm{O}\right)_{6}$ cluster. Then, a sharp decrease of $\Delta \mathrm{H}$ at $\mathrm{Br}^{-}\left(\mathrm{H}_{2} \mathrm{O}\right)_{8}$, where three more hydrogen bonds are formed.

As mentioned above, stepwise trend in $\Delta \mathrm{H}$ for the minimum energy $S$ type isomer can be explained through the above sequence of newly formed hydrogen bonds due to the hydrogen bonds are formed not only between solute and solvent molecules, but also among the water molecules themselves. Compared with the prior size of cluster, the additional water monomer could weaken the ion-solvent interactions and thus the stepwise $\Delta \mathrm{H}$ may gradually decreases with the increasing cluster size.

\section{Spectroscopic Signatures}

\section{Photoelectron Spectral Simulations}

The calculated vertical detachment energies (VDEs) under different levels of theory together with their corresponding experimental determined VDEs and the previous theoretical VDEs are presented in Figure 4 and Table S1. The experimental VDEs were determined by photoelectron spectroscopy (PES). ${ }^{5,6}$ The VDE increases with the increasing cluster size. There is good agreement between the employed theoretically determined values and the experimental values. Furthermore, the VDEs 
obtained from the B3LYP level are also in great agreement with the values obtained from the MP2 level. The adiabatic detachment energies (ADEs) are consistent with the VDEs and a little smaller $(\sim 0.1-0.2 \mathrm{eV})$ than the VDEs. A previous theoretical study $^{25}$ showed that the VDE increase from $n=1$ to $n=5$ and then decrease at $n=6$, which is in disagreement with the experimental results and our findings, as shown in Fig.4. This is also demonstrated that the theoretical method (BH-DFT) we employed is effective in predicting structures and energetics.

To direct compare with the experimental spectra, we simulated the PES spectra of the minimum energy isomer of each size. The simulated spectra revealed that the electron binding energy monotonically increases with the cluster size up to $n=8$, as shown in Fig. 5. Previous study showed that the experimental PES spectra are all broad, ${ }^{5}$ and the contributions may from the various isomers. However, the simulated PES spectra are relatively simple and contain one or two unresolved peaks because of the simulated spectra are density of state (DOS) spectra to some extent and exclude the excited electronic states.

\section{Infrared Spectra Simulations}

The vibrational modes of $\mathrm{Br}^{-}\left(\mathrm{H}_{2} \mathrm{O}\right)_{n}, \mathrm{n}=1-8$ clusters are detected by the simulated infrared (IR) spectroscopy (Fig. 6), the IR spectra of pure water clusters $\left(\mathrm{H}_{2} \mathrm{O}\right)_{n}$, $n=1-9$ are also shown in Fig. S3. In order to comparison, the details of vibrational frequencies are presented in Tables S2-S3 in the supplementary materials.

The simulated spectra are plotted in the range from 5 to $4000 \mathrm{~cm}^{-1}$, which include most of the IR vibrational modes, such as rocking, bending, and stretching. It has been found that, the overall feature in $\mathrm{Br}^{-}\left(\mathrm{H}_{2} \mathrm{O}\right)_{\mathrm{n}}$ spectra is the gain in intensity of $\mathrm{O}-\mathrm{H}^{\cdots} \mathrm{Br}^{-}$stretch at the expense of $\mathrm{O}-\mathrm{H} \cdots \mathrm{O}$ stretch of water. This is due to strengthening of ionic-hydrogen bonds and is marked by a large red shift of the O-H stretching mode in the $\operatorname{Br}^{-}\left(\mathrm{H}_{2} \mathrm{O}\right)_{\mathrm{n}}$ cluster system. These red shifted peaks are important in the $\mathrm{O}-\mathrm{H}^{\cdots} \mathrm{Br}^{-}$interactions since they possess typical spectroscopic signatures. Thus, the present discussion on the hydrated bromide cluster is based on 
the $\mathrm{O}-\mathrm{H}$ stretching.

The detailed vibrational frequency shifts for the minimum energy isomer of $\mathrm{Br}^{-}\left(\mathrm{H}_{2} \mathrm{O}\right)_{n}, \mathrm{n}=1-8$ clusters in $\mathrm{O}-\mathrm{H}$ stretching region are shown in Table 4. For comparison, the experimental values given by the Johnson group ${ }^{21}$ as well as the theoretical results obtained by Neogi et al. ${ }^{25}$ are also presented. As shown in Table 4, the O-H stretching frequencies of $\mathrm{Br}^{-}\left(\mathrm{H}_{2} \mathrm{O}\right)_{n}$ clusters are classified as follows: (1) hydrogen bonded to another water $\left(\mathrm{O}-\mathrm{H}_{\mathrm{w}}\right),(2)$ hydrogen bonded to a bromide atom $\left(\mathrm{O}-\mathrm{H}_{\mathrm{b}}\right)$, and (3) the non-bonded free molecules $\left(\mathrm{O}-\mathrm{H}_{\mathrm{f}}\right)$, respectively.

For the $\mathrm{Br}^{-}\left(\mathrm{H}_{2} \mathrm{O}\right)_{\mathrm{n}}$ clusters, the non-bonded free $\left(\mathrm{O}-\mathrm{H}_{\mathrm{f}}\right)$ frequency remains almost constant, the $\mathrm{O}-\mathrm{H}^{\cdots} \cdot \mathrm{Br}^{-}$bond $\left(\mathrm{O}-\mathrm{H}_{\mathrm{b}}\right)$ is extended significantly with respect to the $\mathrm{Br}^{-}$ ion, and the $\mathrm{O}-\mathrm{H}_{\mathrm{w}}$ stretching frequencies showed a large red-shift compared to the pure water molecules. The magnitude of the red-shift observed varies with the size of the clusters. For the hydrated bromide clusters, the extent of the shift follows the trend: $\mathrm{O}-\mathrm{H}_{\mathrm{f}}<\mathrm{O}-\mathrm{H}_{\mathrm{w}}<\mathrm{O}-\mathrm{H}_{\mathrm{b}}$. The $\mathrm{O}-\mathrm{H}$ stretching frequency shows probable structural arrangement when compared with the experimental value. Because the $\mathrm{O}-\mathrm{H}_{\mathrm{b}}$ strength is dependent on the strength of the hydrogen-halogen interaction, the bonding features can be interpreted.

The experimental results from the Johnson group ${ }^{21}$ showed small blue shifts in the positions of $\mathrm{O}-\mathrm{H}^{\cdots} \mathrm{Br}^{-}$stretches as the cluster size increased from $\mathrm{n}=3$ to 6 . The blue-shifted $\mathrm{O}-\mathrm{H}_{\mathrm{b}}$ stretch can be explained on the basis that an increase in the number of water molecules in the cluster allows the $\mathrm{O}-\mathrm{H}_{\mathrm{w}}$ bonds to regain strength with slight weakening of the $\mathrm{O}-\mathrm{H}_{\mathrm{b}}$ bonds. Our calculated vibrational frequencies are consistent with the experimental results; however, the frequencies from our theoretical predictions are slightly blue-shifted relative to the experimental frequencies. This blue-shift could be attributed to the harmonic approximation used in the frequency calculation.

As shown in Table 4, no O- $\mathrm{H}_{\mathrm{f}}$ frequencies were found for the $\mathrm{Br}^{-}\left(\mathrm{H}_{2} \mathrm{O}\right)_{\mathrm{n}}(\mathrm{n}=3,4,6)$ clusters, because of these structures are more compact and no non-bonded free 
molecules are formed. Compared with the theoretical results obtained by Neogi group,${ }^{25}$ the current study yields fewer stretching frequencies. This could be attributed to the different theoretical method used and slight difference exists in structures.

\section{Temperature Dependence and Conformational Population}

The global minimum has the greatest weight in the ensemble of energetically accessible conformers at $0 \mathrm{~K}$. However, as the systems grow larger, the energy difference between the global minima and other competing local minima decrease. In addition, temperature effects also contribute to the stability order alternation of isomers. Hence, studying the temperature dependence effects of isomer contributions provides a more accurate picture of the relative isomer stability.

In previous studies, researchers ${ }^{35,51-53}$ showed that the thermodynamic properties of clusters depend on temperatures, and the temperature effects contributed to the cluster formation. For experimentalists, it is difficulty to perform the relevant experiments at low temperatures, because of the wall loss problem. ${ }^{54}$ With quantum chemistry calculations, we can obtain the data, and the following results aid in predicting the effect of temperature on the formation of $\mathrm{Br}^{-}\left(\mathrm{H}_{2} \mathrm{O}\right)_{\mathrm{n}}$ clusters.

The change in Gibbs free energy with temperatures from 50 to $450 \mathrm{~K}$ could have a large influence on the relative populations of different isomers; thus, an effect of temperature on the relative populations of isomers for $\mathrm{Br}^{-}\left(\mathrm{H}_{2} \mathrm{O}\right)_{n}(\mathrm{n}=3-8)$ is expected. The equations to calculate their relative populations at various temperatures are listed in follows:

$$
\begin{gathered}
p_{n}^{i}=\frac{\exp \left(-\frac{\Delta \Delta G_{n}^{i}}{R T}\right)}{\sum_{i} \exp \left(-\frac{\Delta \Delta G_{n}^{i}}{R T}\right)} \\
\Delta G_{n}^{i}=G_{n}^{i}-G^{B r^{-}}-n G^{W} \\
\Delta \Delta G_{n}^{i}=\Delta G_{n}^{i}-\min \left\{\Delta G_{n}^{i}\right\}
\end{gathered}
$$

Where $n$ and $i$ represent the number of water molecule in a cluster and the isomer order, respectively. $\mathrm{Br}^{-}$and $\mathrm{W}$ are separately given for the abbreviation of bromide 
ion and water. $p_{n}^{i}$ is the relative population of the $i$ th isomer at one cluster size, $\Delta \Delta G_{n}^{i}$ is the Gibbs free energy of the $i$ th isomer compared to the most stable one, $R$ is the ideal gas constant, and $T$ is the temperature. The conformational population depending on the temperature variance for $\mathrm{Br}^{-}\left(\mathrm{H}_{2} \mathrm{O}\right)_{n}(n=3-8)$ is shown in Figs. 7 and 8. For each case of $\mathrm{Br}^{-}\left(\mathrm{H}_{2} \mathrm{O}\right)_{n}$ cluster, the weight of the lowest energy isomer decreases, whereas the roles of the other low-lying isomers become competitive as the temperature increases.

For the case of $\mathrm{Br}^{-}\left(\mathrm{H}_{2} \mathrm{O}\right)_{3}$ cluster, as shown in Fig. 7, the weight of the minimum energy isomer gradually decreases with the increasing temperatures. Isomer III-a weighs more than any other isomers below $80 \mathrm{~K}$, and then weighs the least above 250 K. Isomer III-b weighs the most between 100-300 K. Isomers III-b, III-c and III-d are competing with each other above $300 \mathrm{~K}$. For $\mathrm{Br}^{-}\left(\mathrm{H}_{2} \mathrm{O}\right)_{4}$, isomers IV-a and IV-g crossover at approximately $175 \mathrm{~K}$; the global minimum IV-a weighs more below 175 $\mathrm{K}$, whereas isomer IV-g weighs more above $175 \mathrm{~K}$. The $S$ type geometry and the $I$ type geometry are competitive at different temperatures. The conformational population of other isomers is mainly unchanged with increasing temperature, except isomer IV-b shows fluctuate between 50 and $150 \mathrm{~K}$.

The global minima of the smaller size clusters are taken as the absolute advantages. In contrast to the $\mathrm{Br}^{-}\left(\mathrm{H}_{2} \mathrm{O}\right)_{3,4}$ cluster, isomers $\mathrm{V}-\mathrm{a}$ and $\mathrm{V}-\mathrm{b}$ of the $\mathrm{Br}^{-}\left(\mathrm{H}_{2} \mathrm{O}\right)_{5}$ cluster occupy almost the same conformational population, 55\% and 45\%, respectively. However, starting at $100 \mathrm{~K}$, the population of isomer V-g (I type) sharply increases with increasing temperature and obtains its highest weight at $300 \mathrm{~K}$ and then remains constant. For $\mathrm{Br}^{-}\left(\mathrm{H}_{2} \mathrm{O}\right)_{6}$, although the population of the global minimum decreases with increasing temperature, it still has the greatest weight among all isomers below $250 \mathrm{~K}$. Above $300 \mathrm{~K}$, isomers VI-g and VI-m (I type) became more prevalent, where VI-m weighs more. The trends of the low-lying isomers VI-b and VI-c are consistent with the global minimum structure.

The global minimum structure VII-a of the $\mathrm{Br}^{-}\left(\mathrm{H}_{2} \mathrm{O}\right)_{7}$ cluster makes up almost 
$100 \%$ of the population at $50 \mathrm{~K}$, but its leading role breaks at approximately $225 \mathrm{~K}$, as shown in Fig. 8. The isomer VII-d weighs more than any other low-lying isomers above $250 \mathrm{~K}$. Moreover, the strong temperature effect could be observed in the less competitive role of VII-c, even though its relative energy is close to the global minimum, $\left(2.433 \mathrm{kcal} \mathrm{mol}^{-1}\right)$. For $\mathrm{Br}^{-}\left(\mathrm{H}_{2} \mathrm{O}\right)_{8}$, with the increasing temperature, the conformational population of isomer VIII-a decreases, whereas isomers VIII-m and VIII-q increase. The population of isomer VIII-q is dominant above $350 \mathrm{~K}$. Isomer VIII-m increases below $200 \mathrm{~K}$, and then decreases above $250 \mathrm{~K}$. The top low-lying isomers, such as VIII-b, VIII-c, and VIII-d, show a relatively weak temperature effect.

As the temperature increases, the weight of the minimum energy isomer is decreases, whereas that of the other low-lying isomers increases. Moreover, the I type geometry shows strong temperature dependence. Previous study indicated that the $S$ type solvation in small halide water clusters at $250-300 \mathrm{~K}$ temperatures is dominant. ${ }^{55}$ Therefore, $S$ type clusters prevail over the $I$ type within the experimental temperature range where each cluster was observed, although $I$ clusters may also be present in some proportion.

\section{E. Bonding Order Analysis}

There has been enormous interest of hydrogen bonds, due to its importance to life. Although the hydrated bromide cluster is a relatively simple molecular system, the interactions present in the clusters are a combined effect of hydrogen bonding $(\mathrm{O}-\mathrm{H} \cdots$ $\mathrm{O})$ and hydrogen-halogen interactions $\left(\mathrm{O}-\mathrm{H}^{\cdots} \mathrm{Br}^{-}\right)$and may lead to many interesting properties.

Bond order is a quantitative description of chemical bonds and has been widely used to understand the nature of molecular electronic structures. However, most chemical bond/non-covalent interaction studies focus on topological analysis, such as atoms in molecules (AIM), and natural bond orbital (NBO) analysis, ${ }^{56}$ there are no direct bond order values for this species. In this study, we thoroughly investigate the Mayer bond order (MBO), ${ }^{57}$ Wiberg bond order (WBO),${ }^{58}$ Fuzzy bond order (FBO),${ }^{59}$ 
Mulliken bond order (MUBO), ${ }^{60}$ Laplacian bond order (LBO), ${ }^{61}$ and the Multi-center bond order $(\mathrm{MCBO})^{62}$ of the series of $\mathrm{Br}^{-}\left(\mathrm{H}_{2} \mathrm{O}\right)_{\mathrm{n}}$ clusters for the hydrogen bonding order and the hydrogen-halogen interaction bonding order at different levels of theory. These bond order analysis methods are the most commonly used methods. All of the bond order calculations are implemented in the Multiwfn code. ${ }^{47}$

Different bond orders as a function of water numbers at B3LYP/cc-pVTZ and B3LYP/aug-cc-pVTZ levels are shown in Figs. 9 and 10. For comparison, the bond orders calculated at the B3LYP/cc-pVDZ and B3LYP/aug-cc-pVDZ levels are also presented in Figs. S5 and S6. To test the accuracy of the method selected here, we calculated the MBO of the $\mathrm{Br}^{-}\left(\mathrm{H}_{2} \mathrm{O}\right)_{1}$ cluster, and the bond orders within the water molecules are 1.094 and 0.873 , which are in agreement with the empirical bond order. The reasonableness of MBO treatment has been validated in a previous study. ${ }^{63}$

Five different bond orders of the hydrogen bond $(\mathrm{O}-\mathrm{H} \cdots \mathrm{O})$ and the hydrogen-halogen interaction $\left(\mathrm{O}-\mathrm{H} \cdots \mathrm{Br}^{-}\right)$under the B3LYP/cc-pVTZ level are shown in Fig. 9. For both the $\mathrm{O}-\mathrm{H}^{\cdots} \mathrm{Br}^{-}$interaction and the $\mathrm{O}-\mathrm{H} \cdots \mathrm{O}$ bonding, the overall trend of each order agrees well with each other. For the hydrogen-halogen interactions (Fig. 9(a)), the $\mathrm{O}-\mathrm{H}^{\cdots} \cdot \mathrm{Br}^{-}$bond length increases and the bond order decreases with increasing water molecules. The WBO gives the maximum value and the MUBO gives the least. The hydrogen bond order O-H $\cdots \mathrm{O}$ (Fig. 9(b)) shows the opposite result compared to the $\mathrm{O}-\mathrm{H} \cdots \mathrm{Br}^{-}$interactions. Although each curve shows small oscillation, the calculated bonding orders increase with increasing water molecules and decreasing bonding lengths. The biggest difference of each bond order of the $\mathrm{O}-\mathrm{H} \cdots \mathrm{O}$ bonding is 0.10 , where the MUBO gives the biggest value and the FBO gives the smallest, which is different from the hydrogen-halogen interaction.

Four different bond orders of both the hydrogen bond $(\mathrm{O}-\mathrm{H} \cdots \mathrm{O})$ and the hydrogen-halogen interaction $\left(\mathrm{O}-\mathrm{H}^{\cdots} \cdot \mathrm{Br}^{-}\right)$are shown in Fig. 10. The Wiberg bond order (WBO) was excluded under the B3LYP/aug-cc-pVTZlevel, since the values are much larger and no comparable with other bond orders. For both the $\mathrm{O}-\mathrm{H}^{\cdots} \mathrm{Br}^{-}$ 
interactions and the $\mathrm{O}-\mathrm{H} \cdots \mathrm{O}$ bonding, the overall trend of each order agrees well with each other, and similar to that obtained under B3LYP/cc-pVTZ level. For the hydrogen-halogen interactions (Fig. 10(a)), the values obtained for MUBO are the least for each size of clusters among all of the analyzed bond orders. For the hydrogen bond order $\mathrm{O}-\mathrm{H} \cdots \mathrm{O}$ (Fig. 10(b)), the results are the opposite of the $\mathrm{O}-\mathrm{H} \cdots \mathrm{Br}^{-}$ interactions. The calculated bonding orders increase with increasing water molecules and decreasing bonding lengths. Similarly, the value obtained by MUBO is the highest for each size of clusters among all of the analyzed bond order methods.

We also calculated the different bond orders under smaller basis set (B3LYP/cc-pVDZ and B3LYP/aug-cc-pVDZ levels) to check whether the bond orders are sensitive to the basis set, as shown in Figs.S5 and S6. It has been found that the values obtained under the B3LYP/aug-cc-pVDZ level are almost the same to those obtained under the B3LYP/aug-cc-pVTZ level, the values obtained under B3LYP/cc-pVDZ are similar to those of B3LYP/cc-pVTZ level, suggested that the bond orders are not sensitive to the basis set. However, the values obtained at the B3LYP/cc-pVTZ level are larger than those obtained at B3LYP/aug-cc-pVTZ level, similar results were also found for the B3LYP/cc-pVDZ and B3LYP/aug-cc-pVDZ levels, suggested that the same method with or without diffusion functions could affect the bond order values.

\section{Conclusions}

BH-DFT method was employed to search for the low-lying isomers of $\mathrm{Br}^{-}\left(\mathrm{H}_{2} \mathrm{O}\right)_{\mathrm{n}}$ $(n=1-8)$ clusters. It was shown that the global minimum of smaller size clusters agrees well with previous studies. For the relatively larger $\mathrm{Br}^{-}\left(\mathrm{H}_{2} \mathrm{O}\right)_{7,8}$ clusters, new global minima were found. In addition, both the surface type and interior type geometries are presented for each size of clusters, and the surface solvation clusters are energetically more stable.

The thermodynamic parameters decrease monotonously with an increasing number of water clusters. The thermodynamics analysis showed that the energy of 
order alternation caused by the entropy effect, which has also been observed in $\mathrm{Cl}^{-}\left(\mathrm{H}_{2} \mathrm{O}\right)_{\mathrm{n}}$ clusters. Additionally, the trend in the enthalpies $(\Delta \mathrm{H})$ of hydration is correlated to the number of newly formed hydrogen bonds.

For each case of the $\mathrm{Br}^{-}\left(\mathrm{H}_{2} \mathrm{O}\right)_{n}$ cluster, the weight of the lowest energy isomer decreases, whereas the role of the other low-lying isomer become competitive as the temperature increases. For different types of geometry, the interior type geometries are dominant at higher temperature. However, the conformational population of $S$ type is prevalentat a temperature close to that of the experiment conditions.

Finally, the different bond order properties have been studied. The overall trends of each bond order analysis method for both the $\mathrm{O}-\mathrm{H}^{\cdots} \cdots \mathrm{Br}^{-}$interaction and the $\mathrm{O}-\mathrm{H} \cdots \mathrm{O}$ bond are in agreement. In general, for the hydrogen-halogen interaction, the $\mathrm{O}-\mathrm{H}^{\cdots} \mathrm{Br}^{-}$ bonding length increases, whereas the bonding order decreases, with an increase in water molecules. The $\mathrm{O}-\mathrm{H} \cdots \mathrm{O}$ bond order shows the opposite result.

\section{ACKNOWLEDGMENT}

The study was supported by grants from the National Natural Science Foundation of China (Grant No. 21403244, 21573241, 41505114, and 41527808), the State Key Program of National Natural Science of China (Grant No. 21133008), the National High Technology Research and Development Program of China (863 Program No. 2014AA06A501) and the "Interdisciplinary and Cooperative Team" of CAS. Acknowledgement is also made to the "Thousand Youth Talents Plan". Part of the computation was performed in EMSL, a national scientific user facility sponsored by the department of Energy's Office of Biological and Environmental Research and located at Pacific Northwest National Laboratory (PNNL), and part of the

computation was performed at the Supercomputing Center of the CAS and Supercomputing Center of USTC. 


\section{Supporting Information}

Predicted vertical detachment energies, vibrational frequencies, bond order values, optimized low-lying isomers of $\mathrm{Br}^{-}\left(\mathrm{H}_{2} \mathrm{O}\right)_{\mathrm{n}}$ clusters, optimized global minima and simulated infrared spectra of $\left(\mathrm{H}_{2} \mathrm{O}\right)_{n}, n=1-9$ clusters, are shown in Supporting Information. This material is available free of charge via the Internet at http://www.journals.elsevier.com.

\section{Reference}

(1) W. H. Robertson, M. A. Johnson, Аnnu. Rev. Phys. Chem. 54 (2003) 173.

(2) X. Sun, B. Li, Q. Zhou, H. Zhang, G. Cheng, X. Zhou, Crystal Growth \& Design8 (2008) 2970.

(3) K. Hiraoka, S. Mizuse, S. Yamabe, J. Phys. Chem. 92 (1988) 3943.

(4) A. Likholyot, J. K. Hovey, T. M. Seward, Geochim. Cosmochim. Acta 69 (2005) 2949.

(5) G. Markovich, S. Pollack, R. Giniger, O. Cheshnovsky, J. Chem. Phys.101 (1994) 9344.

(6) G. Markovich, S. Pollack, R. Giniger, O. Cheshnovsky, J. Chem. Phys. 95 (1991) 9416.

(7) P. Ayotte, G. H. Weddle, M. A. Johnson, J. Chem. Phys. 110 (1999) 7129.

(8) P. Ayotte, S. B. Nielsen, G. H. Weddle, M. A. Johnson, S. S. Xantheas, J. Phys. Chem. A 103 (1999) 10665.

(9) J. H. Choi, K. T. Kuwata, Y. B. Cao, M. Okumura, J. Phys. Chem. A 102 (1998) 503.

(10) L. Lehr, M. T. Zanni, C. Frischkorn, R. Weinkauf, D. M. Neumark, Science 284 (1999) 635.

(11) W. D. Vonfraunberg, G. Drechsler, C. Bassmann, U. Boesl, E. W. Schlag, Int. J. Mass Spectrom. Ion Processes 133 (1994) 211.

(12) D. Serxner, C. E. H. Dessent, M. A. Johnson, J. Chem. Phys.105 (1996) 7231.

(13) P. Ayotte, J. A. Kelley, S. B. Nielsen, M. A. Johnson, Chem. Phys. Lett. 316 (2000) 455.

(14) J. A. Kelley, J. M. Weber, K. M. Lisle, W. H. Robertson, P. Ayotte, M. A. Johnson, Chem. Phys. Lett. 327 (2000) 1.

(15) C. G. Bailey, J. Kim, C. E. H. Dessent, M. A. Johnson, Chem. Phys. Lett. 269 (1997) 122.

(16) P. Ayotte, G. H. Weddle, J. Kim, M. A. Johnson, Chem. Phys. 239 (1998) 485.

(17) P. Ayotte, G. H. Weddle, J. Kim, M. A. Johnson, J. Am. Chem. Soc.120 (1998) 12361.

(18) E. A. Price, N. I. Hammer, M. A. Johnson, J. Phys. Chem. A 108 (2004) 3910.

(19) J. R. Roscioli, E. G. Diken, M. A. Johnson, S. Horvath, A. B. McCoy, J. Phys. Chem. A 110 (2006) 4943.

(20) P. Ayotte, G. H. Weddle, J. Kim, J. Kelley, M. A. Johnson, J. Phys. Chem. A 103 (1999) 443.

(21) P. Ayotte, C. G. Bailey, G. H. Weddle, M. A. Johnson, J. Phys. Chem. A 102 (1998) 3067.

(22) W. L. Jorgensen, J. Chandrasekhar, J. D. Madura, R. W. Impey, M. L. Klein, J. Chem. Phys. 
79 (1983) 926.

(23) W. L. Jorgensen, J. Am. Chem. Soc. 103 (1981) 335.

(24) D. J. Wales, M. P. Hodges, Chem. Phys. Lett. 286 (1998) 65.

(25) S. G. Neogi, P. Chaudhury, J. Comput. Chem. 34 (2013) 471.

(26) S. Jiang, Y.-R.Liu, T. Huang, H. Wen, K.-M.Xu, W.-X.Zhao, W.-J. Zhang, W. Huang, J. Comput. Chem. 35 (2014) 159.

(27) S. Jiang, T. Huang, Y.-R.Liu, K.-M.Xu, Y. Zhang, Y.-Z.Lv, W. Huang, Phys. Chem. Chem. Phys.16 (2014) 19241.

(28) E. Ramos-Cordoba, D. S. Lambrecht, M. Head-Gordon, Faraday Discuss.150 (2011) 345.

(29) J. Kim, H. M. Lee, S. B. Suh, D. Majumdar, K. S. Kim, J. Chem. Phys.113(2000) 5259.

(30) D. Majumdar, J. Kim, K. S. Kim, J. Chem. Phys.112 (2000) 101.

(31) H. M. Lee, D. Kim, K. S. Kim, J. Chem. Phys.116 (2002) 5509.

(32) H. M. Lee, K. S. Kim, J. Chem. Phys. 114(2001) 4461.

(33) S. Jahangiri, G. Dolgonos, T. Frauenheim, G. H. Peslherbe, J. Chem. Theo.Comput.9 (2013) 3321.

(34) M. Masamura, J. Chem. Phys.118 (2003) 6336.

(35) J. E. Combariza, N. R. Kestner, J. Jortner, J. Chem. Phys. 100 (1994) 2851.

(36) R. W. Gora, S. Roszak, J. Leszczynski, J. Chem. Phys. Lett. 325 (2000) 7.

(37) R. Ayala, J. M. Martinez, R. R. Pappalardo, H. Saint-Martin, I. Ortega-Blake, E. S. Marcos, J. Chem. Phys. 117 (2002) 10512.

(38) H. Wen, Y.-R.Liu, T. Huang, K.-M.Xu, W.-J.Zhang, W. Huang, L.-S.Wang, J. Chem. Phys. 138 (2013) 174303.

(39)K.-M. Xu, T. Huang, H. Wen, Y.-R. Liu, Y.-B. Gai, W.-J. Zhang, W. Huang, Rsc Adv. 3 (2013) 24492.

(40) L.-L. Yan, Y.-R.Liu, T. Huang, S. Jiang, H. Wen, Y.-B. Gai, W.-J. Zhang, W. Huang, J. Chem. Phys. 139 (2013) 244312.

(41) H. Wen, Y.-R.Liu, K.-M.Xu, T. Huang, C.-J.Hu, W.-J.Zhang, W. Huang, Rsc Adv. 4 (2014) 15066.

(42) Y.-R. Liu, H. Wen, T. Huang, X.-X. Lin, Y.-B. Gai, C.-J. Hu, W.-J. Zhang, W. Huang, J. Phys. Chem. A, 118 (2014) 508.

(43) J. P. Perdew, K. Burke, M. Ernzerhof, Phys. Rev.Lett. 77(1996) 3865.

(44) B. Delley, J. Chem. Phys. 92 (1990) 508.

(45) K. Raghavachari, G. W. Trucks, J. Chem. Phys. 91 (1989) 1062.

(46) G. W. T. M. J. Frisch, H. B. Schlegel, G. E. Scuseria, , J. R. C. M. A. Robb, G. Scalmani, V. Barone, B. Mennucci, , H. N. G. A. Petersson, M. Caricato, X. Li, H. P. Hratchian, J. B. A. F. Izmaylov, G. Zheng, J. L. Sonnenberg, M. Hada, et al, Gaussian 09, Revision A.02, Gaussian, Inc., Wallingford CT, 2009.

(47) T. Lu, F. Chen, J. Comput. Chem.33 (2012) 580.

(48) C. Ishibashi, S. Iwata, K. Onoe, H. Matsuzawa, J. Phys. Chem.A 119 (2015) 10241.

(49) R. Ayala, J. M. Martinez, R. R. Pappalardo, E. S. Marcos, J. Phys. Chem.A 104 (2000) 2799.

(50) M. Arshadi, R. Yamdagni, P. Kebarle, J. Phys. Chem.74 (1970) 1475.

(51) J. S. Kim, B. J. Mhin, S. J. Lee, K. S. Kim, Chem. Phys. Lett.219 (1994) 243.

(52) B. J. Mhin, S. J. Lee, K. S. Kim, Phys. Rev. A,48 (1993) 3764.

(53) H. M. Lee, S. B. Suh, J. Y. Lee, P. Tarakeshwar, K. S. Kim, J. Chem. Phys.112(2000) 9759. 
(54) L. Torpo, T. Kurten, H. Vehkamaki, K. Laasonen, M. R. Sundberg, M. Kulmala, J. Phys. Chem. A111 (2007) 10671.

(55) S. Raugei, M. L. Klein, J. Phys. Chem. B106 (2002) 11596.

(56) D. Mani, E. Arunan, J. Phys. Chem.A118 (2014) 10081.

(57) I. Mayer, J. Comput. Chem.28 (2007) 204.

(58) K. B. Wiberg, Tetrahedron24 (1968) 1083.

(59) I. Mayer, P. Salvador, Chem. Phys. Lett.383 (2004)368.

(60) R. S. Mulliken, J. Chem. Phys.23 (1955)1841.

(61) M. Giambiagi, M. S. de Giambiagi, K. C. Mundim, Struct.Chem.1 (1990) 423.

(62) T. Lu, F. Chen, J. Comput. Chem.33 (2012) 580.

(63) I. Mayer, Chem. Phys. Lett.544 (2012) 83. 
Table 1 The binding energies at $0 \mathrm{~K}\left(\Delta \mathrm{E}_{\mathrm{e}}{ }^{0 \mathrm{~K}}\right)$, ZPE-corrected relative energies at $0 \mathrm{~K}$ $\left(\Delta \mathrm{E}_{0}{ }^{0 \mathrm{~K}}\right)$, Gibbs free energy at $298.15 \mathrm{~K}\left(\Delta \mathrm{G}^{298.15 \mathrm{~K}}\right)$, enthalpies at $298.15 \mathrm{~K}\left(\Delta \mathrm{H}^{298.15 \mathrm{~K}}\right)$, thermal energies at $298.15 \mathrm{~K}\left(\Delta \mathrm{U}^{298.15 \mathrm{~K}}\right)$, and entropies at $298.15 \mathrm{~K}\left(\Delta \mathrm{S}^{298.15 \mathrm{~K}}\right)$ for $\mathrm{Br}^{-}\left(\mathrm{H}_{2} \mathrm{O}\right)_{\mathrm{n}}, \mathrm{n}=1-4$ and the experimental enthalpies $\left(\Delta \mathrm{H}_{\text {exp }}\right)$ and Gibbs free energies $\left(\Delta \mathrm{G}_{\mathrm{exp}}\right)$. (in kcal mol$\left.{ }^{-1}\right)$

\begin{tabular}{|c|c|c|c|c|c|c|c|c|}
\hline Isomers & $\Delta \mathbf{E}_{\mathrm{e}}^{0 \mathrm{~K}}$ & $\Delta \mathrm{E}_{0}{ }^{0 \mathrm{~K}}$ & $\Delta G^{298.15 K}$ & $\Delta \mathbf{H}^{298.15 K}$ & $\Delta \mathbf{U}^{298.15 K}$ & $\Delta S^{298.15 K}$ & $\Delta \mathbf{H}_{\exp }^{[a]}$ & $\Delta \mathbf{G}_{\exp }^{[a]}$ \\
\hline $\mathrm{I}-\mathrm{a}$ & -12.27 & -11.18 & -5.97 & -11.93 & -11.34 & -45.64 & $-11.7,-12.6$ & $-7.3,-7.0$ \\
\hline II-a & -24.69 & -21.25 & -9.90 & -22.69 & -21.51 & -63.90 & $-23.3,-24.9$ & $-13.6,-12.5$ \\
\hline III-a & -38.01 & -31.60 & -11.15 & -33.95 & -32.18 & -80.62 & $-34.7,-36.4$ & $-18.2,-16.6$ \\
\hline III-b & -36.85 & -31.17 & -12.21 & -33.19 & -31.41 & -82.44 & & \\
\hline III-c & -35.81 & -30.24 & -12.09 & -32.18 & -30.40 & -83.32 & & \\
\hline III-d & -35.21 & -29.92 & -11.82 & -31.69 & -29.92 & -83.55 & & \\
\hline IV-a & -50.54 & -40.91 & -15.39 & -44.28 & -41.91 & -98.25 & -45 & -19.5 \\
\hline IV-b & -49.37 & -40.59 & -14.73 & -43.64 & -41.27 & -99.23 & & \\
\hline IV-c & -47.50 & -39.22 & -15.36 & -41.86 & -39.49 & -100.82 & & \\
\hline IV-d & -47.83 & -39.58 & -15.30 & -42.24 & -39.87 & -101.20 & & \\
\hline IV-e & -47.37 & -39.53 & -14.54 & -41.99 & -39.62 & -101.26 & & \\
\hline IV-f & -47.83 & -39.58 & -16.11 & -42.24 & -39.87 & -101.20 & & \\
\hline IV-g & -47.50 & -39.23 & -13.73 & -41.87 & -39.50 & -100.83 & & \\
\hline IV-h & -46.85 & -38.82 & -15.29 & -41.34 & -38.97 & -101.08 & & \\
\hline IV-i & -45.84 & -38.29 & -16.84 & -40.57 & -38.20 & -102.4 & & \\
\hline
\end{tabular}

[a]The first experimental values are obtained by Hiraoka et al. [Ref. 3] and the second are obtained by Arshadi et. al. [Ref. 48]. 
Table 2 The binding energies at $0 \mathrm{~K}\left(\Delta \mathrm{E}_{\mathrm{e}}{ }^{0 \mathrm{~K}}\right)$, ZPE-corrected relative energies at $0 \mathrm{~K}$ $\left(\Delta \mathrm{E}_{0}{ }^{0 \mathrm{~K}}\right)$, Gibbs free energy at $298.15 \mathrm{~K}\left(\Delta \mathrm{G}^{298.15 \mathrm{~K}}\right)$, enthalpies at $298.15 \mathrm{~K}\left(\Delta \mathrm{H}^{298.15 \mathrm{~K}}\right)$, thermal energies at $298.15 \mathrm{~K}\left(\Delta \mathrm{U}^{298.15 \mathrm{~K}}\right)$, and entropies at $298.15 \mathrm{~K}\left(\Delta \mathrm{S}^{298.15 \mathrm{~K}}\right)$ for $\mathrm{Br}^{-}\left(\mathrm{H}_{2} \mathrm{O}\right)_{5}$ and $\mathrm{Br}^{-}\left(\mathrm{H}_{2} \mathrm{O}\right)_{6}$. (in kcal $\mathrm{mol}^{-1}$ )

\begin{tabular}{|c|c|c|c|c|c|c|}
\hline Isomers & $\Delta E_{e} e^{0 K}$ & $\Delta E_{0}{ }^{0 K}$ & $\Delta G^{298.15 K}$ & $\Delta \mathbf{H}^{298.15 K}$ & $\Delta \mathbf{U}^{298.15 K}$ & $\Delta S^{298.15 K}$ \\
\hline $\mathrm{V}-\mathrm{a}$ & -62.17 & -50.48 & -23.10 & -54.41 & -51.45 & -116.54 \\
\hline $\mathrm{V}-\mathrm{b}$ & -62.05 & -50.44 & -22.25 & -54.32 & -51.36 & -116.78 \\
\hline V-c & -57.47 & -47.29 & -22.10 & -50.26 & -47.29 & -121.08 \\
\hline V-d & -60.21 & -49.09 & -23.28 & -52.74 & -49.78 & -117.39 \\
\hline V-e & -59.21 & -48.07 & -24.44 & -51.63 & -48.67 & -117.66 \\
\hline V-f & -58.86 & -48.29 & -21.50 & -51.36 & -48.39 & -121.73 \\
\hline $\mathrm{V}-\mathrm{g}$ & -58.91 & -48.04 & -21.23 & -51.45 & -48.49 & -117.90 \\
\hline $\mathrm{V}-\mathrm{h}$ & -58.58 & -47.87 & -23.00 & -51.24 & -48.28 & -118.61 \\
\hline $\mathrm{V}-\mathrm{i}$ & -58.34 & -47.81 & -22.32 & -50.98 & -48.02 & -119.19 \\
\hline $\mathrm{V}-\mathrm{j}$ & -58.34 & -47.67 & -23.38 & -51.55 & -48.59 & -116.69 \\
\hline V-k & -58.18 & -47.51 & -22.84 & -50.87 & -47.91 & -119.08 \\
\hline V-1 & -58.24 & -47.90 & -21.09 & -51.10 & -48.14 & -118.59 \\
\hline $\mathrm{V}-\mathrm{m}$ & -57.61 & -46.91 & -22.73 & -50.22 & -47.26 & -119.36 \\
\hline $\mathrm{V}-\mathrm{n}$ & -57.50 & -47.68 & -21.00 & -50.53 & -47.57 & -120.32 \\
\hline $\mathrm{V}-\mathrm{o}$ & -56.65 & -46.64 & -22.48 & -49.45 & -46.49 & -122.06 \\
\hline & & & & & & \\
\hline VI-a & -73.43 & -58.90 & -28.41 & -63.60 & -60.05 & -134.52 \\
\hline VI-b & -72.97 & -59.01 & -28.54 & -63.51 & -59.96 & -134.38 \\
\hline VI-c & -72.81 & -58.77 & -28.27 & -63.40 & -59.85 & -134.44 \\
\hline VI-d & -71.59 & -57.62 & -27.05 & -62.12 & -58.56 & -135.90 \\
\hline VI-e & -71.51 & -57.54 & -26.99 & -62.05 & -58.49 & -137.23 \\
\hline VI-f & -71.28 & -56.87 & -25.61 & -61.87 & -58.31 & -139.47 \\
\hline VI-g & -71.10 & -57.57 & -28.76 & -61.75 & -58.20 & -136.69 \\
\hline VI-h & -71.04 & -56.67 & -26.01 & -61.32 & -57.76 & -134.51 \\
\hline VI-i & -70.74 & -57.18 & -27.83 & -61.40 & -57.85 & -134.60 \\
\hline VI-j & -70.45 & -56.80 & -27.39 & -61.06 & -57.51 & -136.00 \\
\hline VI-k & -70.09 & -56.59 & -27.89 & -60.77 & -57.22 & -134.26 \\
\hline VI-1 & -69.84 & -56.36 & -25.65 & -61.23 & -57.68 & -137.41 \\
\hline VI-m & -69.77 & -56.83 & -28.55 & -60.71 & -57.16 & -136.11 \\
\hline VI-n & -69.68 & -56.01 & -26.73 & -60.20 & -56.65 & -141.31 \\
\hline
\end{tabular}


Table 3 The binding energies at $0 \mathrm{~K}\left(\Delta \mathrm{E}_{\mathrm{e}}{ }^{0 \mathrm{~K}}\right)$, ZPE-corrected relativeenergies at $0 \mathrm{~K}$ $\left(\Delta \mathrm{E}_{0}{ }^{0 \mathrm{~K}}\right)$, Gibbs free energy at $298.15 \mathrm{~K}\left(\Delta \mathrm{G}^{298.15 \mathrm{~K}}\right)$, enthalpies at $298.15 \mathrm{~K}\left(\Delta \mathrm{H}^{298.15 \mathrm{~K}}\right)$, thermal energies at $298.15 \mathrm{~K}\left(\Delta \mathrm{U}^{298.15 \mathrm{~K}}\right)$, and entropies at $298.15 \mathrm{~K}\left(\Delta \mathrm{S}^{298.15 \mathrm{~K}}\right)$ for $\mathrm{Br}^{-}\left(\mathrm{H}_{2} \mathrm{O}\right)_{7}$ and $\mathrm{Br}^{-}\left(\mathrm{H}_{2} \mathrm{O}\right)_{8}$. (in kcal mol${ }^{-1}$ )

\begin{tabular}{|c|c|c|c|c|c|c|}
\hline Isomers & $\Delta \mathrm{E}_{\mathrm{e}}^{0 \mathrm{~K}}$ & $\Delta \mathrm{E}_{0}{ }^{0 \mathrm{~K}}$ & $\Delta G^{298.15 K}$ & $\Delta H^{298.15 K}$ & $\Delta \mathbf{U}^{298.15 K}$ & $\Delta S^{298.15 K}$ \\
\hline VII-a & -85.78 & -68.38 & -33.73 & -75.48 & -70.33 & -149.54 \\
\hline VII-b & -84.80 & -67.66 & -32.92 & -74.45 & -69.30 & -150.77 \\
\hline VII-c & -83.34 & -65.99 & -33.24 & -73.70 & -67.55 & -150.84 \\
\hline VII-d & -83.11 & -66.92 & -33.51 & -74.07 & -67.93 & -152.72 \\
\hline VII-e & -83.07 & -66.47 & -32.94 & -74.81 & -67.66 & -152.42 \\
\hline VII-f & -82.61 & -65.93 & -33.04 & -73.29 & -67.14 & -153.67 \\
\hline VII-g & -82.00 & -65.83 & -33.23 & -74.99 & -66.84 & -151.79 \\
\hline VII-h & -81.63 & -64.61 & -32.60 & -75.10 & -65.96 & -153.49 \\
\hline VII-i & -81.58 & -65.32 & -31.78 & -75.41 & -66.26 & -151.83 \\
\hline VII-j & -81.41 & -65.25 & -31.46 & -73.27 & -66.12 & -154.28 \\
\hline VII-k & -81.40 & -64.74 & -32.48 & -75.12 & -65.97 & -153.84 \\
\hline VII-1 & -81.00 & -64.28 & -33.36 & -72.82 & -65.68 & -154.93 \\
\hline VII-m & -80.98 & -64.65 & -31.40 & -72.76 & -65.61 & -153.63 \\
\hline VIII-a & -95.57 & -75.63 & -37.70 & -82.03 & -77.29 & -168.68 \\
\hline VIII-b & -95.27 & -75.41 & -37.30 & -81.87 & -77.13 & -168.81 \\
\hline VIII-c & -95.05 & -75.83 & -36.97 & -81.89 & -77.15 & -168.29 \\
\hline VIII-d & -94.76 & -75.26 & -36.19 & -81.61 & -76.87 & -169.11 \\
\hline VIII-e & -94.65 & -74.82 & -34.56 & -81.28 & -76.54 & -169.77 \\
\hline VIII-f & -94.50 & -75.17 & -36.34 & -81.34 & -76.60 & -169.33 \\
\hline VIII-g & -94.43 & -74.94 & -35.63 & -81.31 & -76.57 & -169.97 \\
\hline VIII-h & -94.31 & -74.89 & -35.86 & -81.11 & -76.37 & -170.00 \\
\hline VIII-i & -94.28 & -75.40 & -36.28 & -81.47 & -76.73 & -172.43 \\
\hline VIII-j & -94.17 & -74.71 & -34.84 & -81.04 & -76.30 & -170.09 \\
\hline VIII-k & -93.92 & -74.31 & -34.75 & -80.65 & -75.91 & -169.54 \\
\hline VIII-1 & -93.88 & -74.74 & -35.78 & -80.83 & -76.09 & -170.01 \\
\hline VIII-m & -93.73 & -75.27 & -37.51 & -81.18 & -76.44 & -171.34 \\
\hline VIII-n & -93.53 & -74.57 & -36.75 & -80.53 & -75.79 & -171.24 \\
\hline VIII-o & -93.44 & -74.38 & -35.27 & -80.37 & -75.63 & -169.92 \\
\hline VIII-p & -92.88 & -73.76 & -34.94 & -79.66 & -74.93 & -170.28 \\
\hline VIII-q & -92.72 & -74.62 & -37.43 & -80.13 & -75.39 & -172.31 \\
\hline VIII-r & -92.70 & -73.60 & -34.72 & -79.73 & -74.99 & -172.00 \\
\hline
\end{tabular}




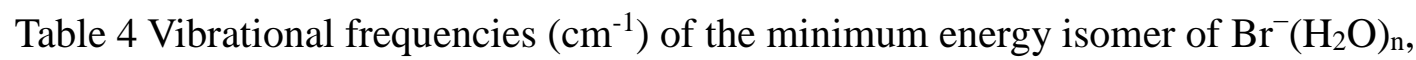
$\mathrm{n}=1-8$ clusters in $\mathrm{O}-\mathrm{H}$ stretching region. The values are obtained at the B3LYP/aug-cc-pVTZ level of theory.

\begin{tabular}{|c|c|c|c|c|c|}
\hline Species & $\mathrm{O}-\mathrm{H}_{\mathrm{b}}$ & $\mathrm{O}-\mathrm{H}_{\mathrm{w}}$ & $\mathrm{O}-\mathrm{H}_{\mathrm{f}}$ & Theo. ${ }^{[\mathrm{a}]}$ & Exp. $^{[\mathrm{b}]}$ \\
\hline $\mathrm{Br}^{-}\left(\mathrm{H}_{2} \mathrm{O}\right)_{1}$ & 3418 & & 3857 & $3325 ; 3476 ; 3873$ & $3241 ; 3368$ \\
\hline $\mathrm{Br}^{-}\left(\mathrm{H}_{2} \mathrm{O}\right)_{2}$ & $3356 ; 3648$ & 3726 & 3848 & $\begin{array}{l}3310 ; 3388 ; 3392 ; \\
3684 ; 3744 ; 3867\end{array}$ & $3250 ; 3373$ \\
\hline $\mathrm{Br}^{-}\left(\mathrm{H}_{2} \mathrm{O}\right)_{3}$ & $3570 ; 3590$ & $3676 ; 3696$ & & $\begin{array}{l}3373 ; 3375 ; 3416 ; \\
3605 ; 3607 ; 3622 ; \\
3698 ; 3716 ; 3717\end{array}$ & $3244 ; 3422$ \\
\hline $\mathrm{Br}^{-}\left(\mathrm{H}_{2} \mathrm{O}\right)_{4}$ & $\begin{array}{c}3638 ; 3650 ; \\
3651 ; 3674\end{array}$ & $\begin{array}{c}3537 ; 3582 \\
3583 ; 3613\end{array}$ & & $\begin{array}{c}3412 ; 3413 ; 3441 ; \\
3574 ; 3614 ; 3617 ; \\
3645 ; 3664 ; 3674 ; \\
3680 ; 3700\end{array}$ & $\begin{array}{c}3245 ; 3466 ; \\
3567\end{array}$ \\
\hline $\mathrm{Br}^{-}\left(\mathrm{H}_{2} \mathrm{O}\right)_{5}$ & $\begin{array}{c}3421 ; 3622 ; \\
3629 ; 3643 ; \\
3722\end{array}$ & $\begin{array}{c}3466 ; 3528 ; \\
3541 ; 3597 ; \\
3622\end{array}$ & 3848 & $\begin{array}{l}3297 ; 3395 ; 3417 \\
3432 ; 3444 ; 3450 ; \\
3503 ; 3555 ; 3578 \\
3627 ; 3650 ; 3659 ; \\
3679 ; 3761 ; 3873\end{array}$ & \\
\hline $\mathrm{Br}^{-}\left(\mathrm{H}_{2} \mathrm{O}\right)_{6}$ & $\begin{array}{l}3500 ; 3615 ; \\
3630 ; 3638 ; \\
3660 ; 3664 ; \\
3718 ; 3731\end{array}$ & $\begin{array}{c}3414 ; 3544 ; \\
3559 ; 3610 \\
3630\end{array}$ & & $\begin{array}{l}3153 ; 3313 ; 3378 ; \\
3391 ; 3416 ; 3435 ; \\
3457 ; 3477 ; 3511 ; \\
3553 ; 3575 ; 3591 ; \\
3628 ; 3668 ; 3678 ; \\
3690 ; 3719 ; 3887 \\
\end{array}$ & \\
\hline $\mathrm{Br}^{-}\left(\mathrm{H}_{2} \mathrm{O}\right)_{7}$ & $\begin{array}{l}3400 ; 3474 ; \\
3538 ; 3545\end{array}$ & $\begin{array}{c}3088 ; 3126 ; \\
3280 ; 3474 ; \\
3486 ; 3634 ; \\
3647 ; 3688 ; \\
3703 \\
\end{array}$ & $3872 ; 3874$ & & \\
\hline $\mathrm{Br}^{-}\left(\mathrm{H}_{2} \mathrm{O}\right)_{8}$ & $\begin{array}{l}3509 ; 3529 ; \\
3559 ; 3585 ; \\
3591 ; 3638 ; \\
3657 ; 3692\end{array}$ & $\begin{array}{c}3340 ; 3369 ; \\
3476 ; 3559 ; \\
3585 ; 3591 ; \\
3595 ; 3726 ; \\
3759\end{array}$ & 3853 & & \\
\hline
\end{tabular}

[a] The values are come from the Neogi group [Ref. 25].

[b] The values are come from the Johnson group [Ref. 21]. 


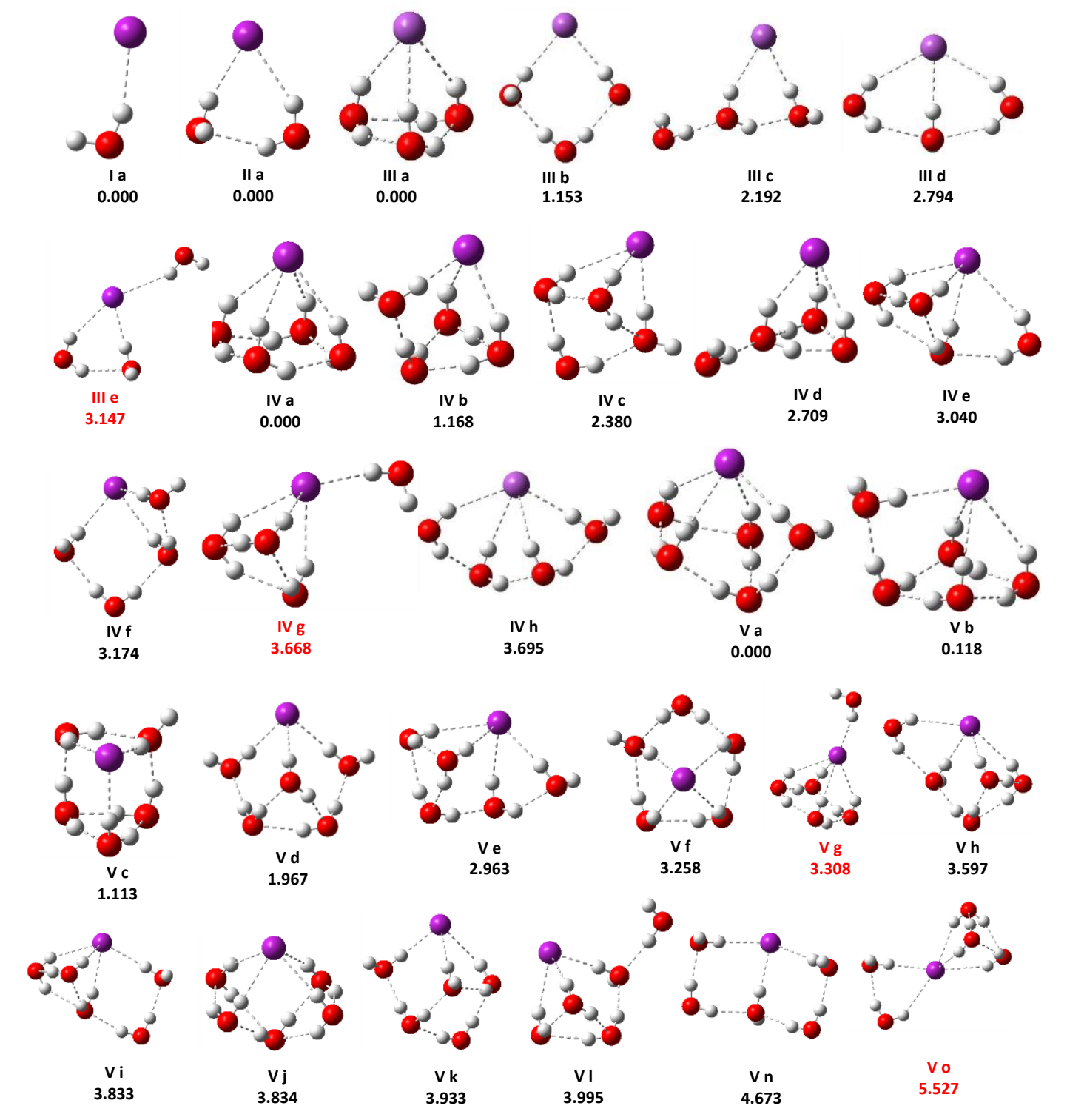

Figure 1 Optimized low-lying geometries of $\operatorname{Br}^{-}\left(\mathrm{H}_{2} \mathrm{O}\right)_{n} \quad(n=1-5)$ at the B3LYP/aug-cc-pVTZ level of theory, ordered by increasing relative electronic energy (in $\mathrm{kcal} \mathrm{mol}^{-1}$ ) to the minimum energy isomer at $0 \mathrm{~K}$ and $1 \mathrm{~atm}$. I, II, $\cdots \cdots \mathrm{V}$ represent $n=1,2, \cdots \cdots 5$. Red text indicates the structures of the interior type geometry. 


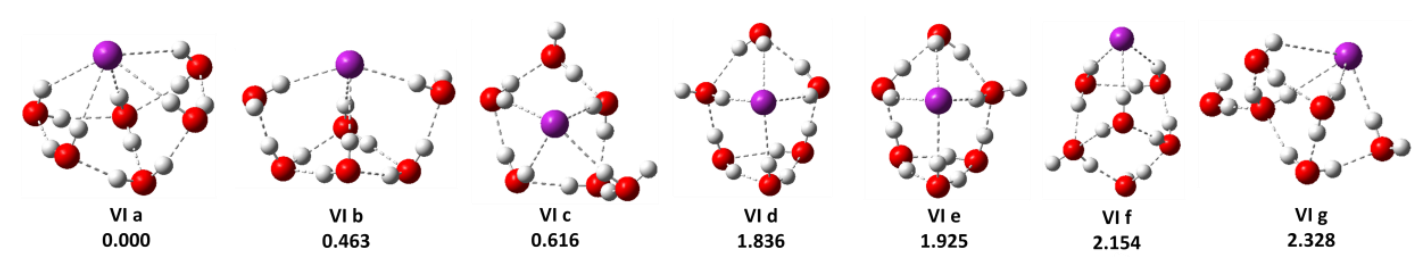

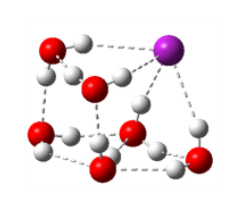

VIh

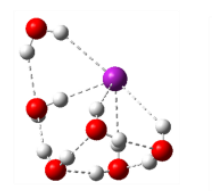

$\mathrm{VI} i$
2.689
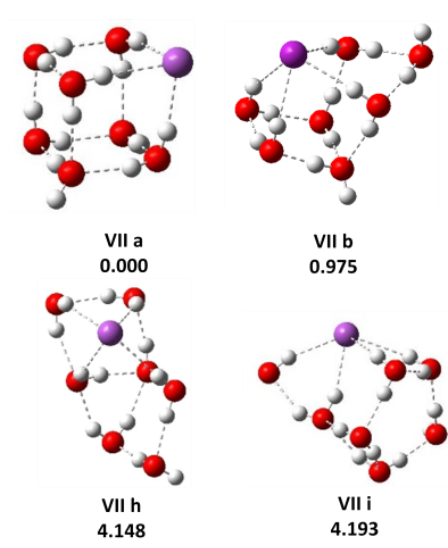
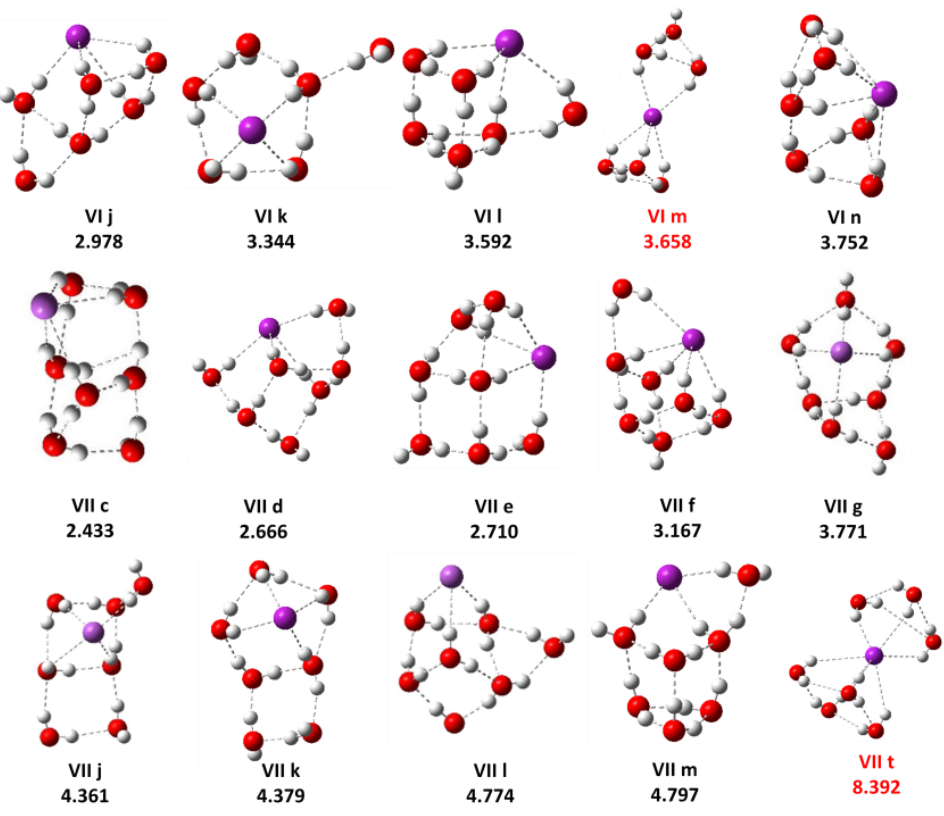

Figure 2 Optimized low-lying geometries of $\operatorname{Br}^{-}\left(\mathrm{H}_{2} \mathrm{O}\right)_{n} \quad(\mathrm{n}=6,7)$ at the B3LYP/aug-cc-pVTZ level of theory, ordered by increasing relative electronic energy (in $\mathrm{kcal} \mathrm{mol}^{-1}$ ) to the minimum energy isomer at $0 \mathrm{~K}$ and $1 \mathrm{~atm}$. VI and VII represent $n=6,7$. Red text indicates structures of the interior type geometry. 

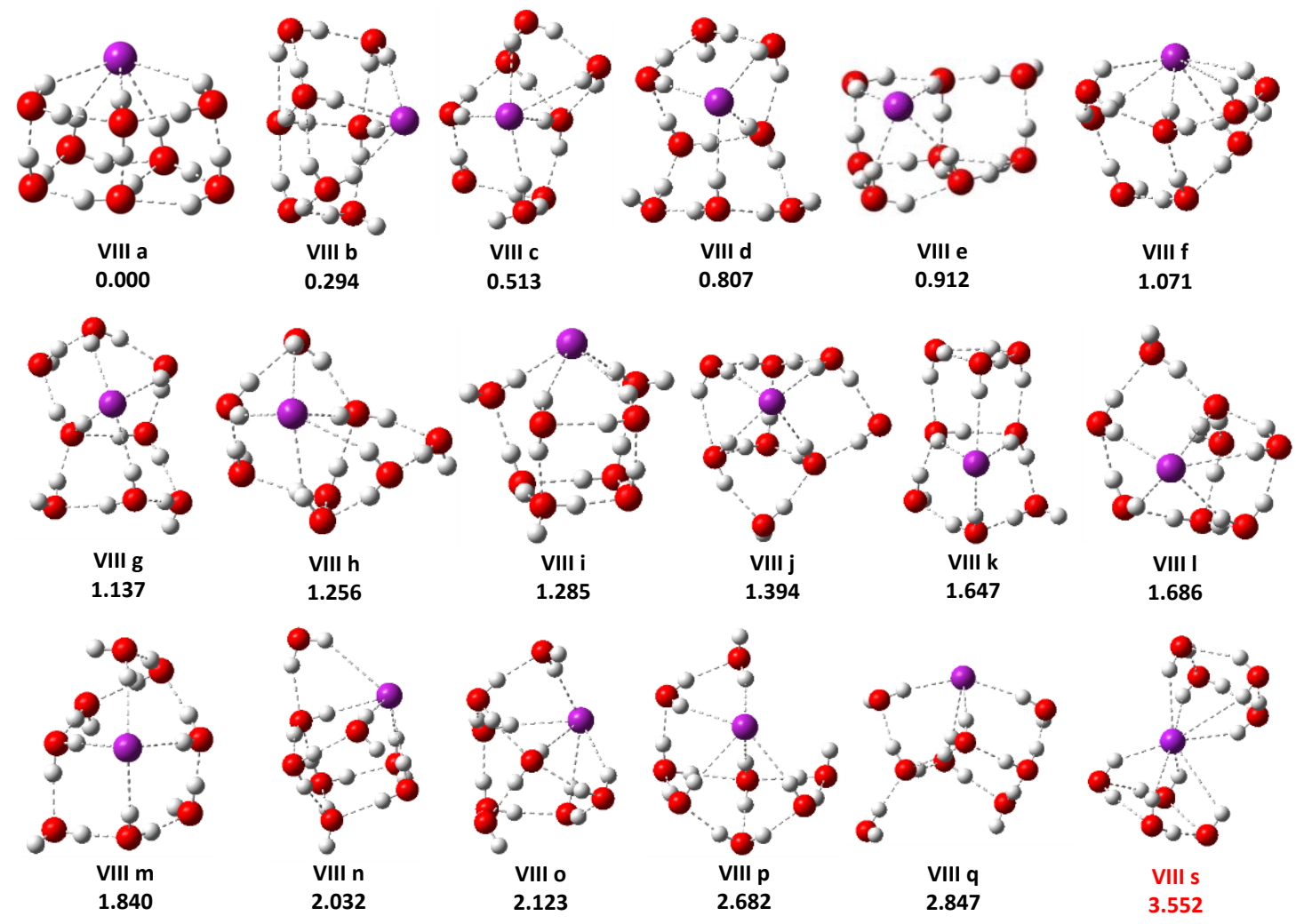

Figure 3 Optimized low-lying geometries of $\operatorname{Br}^{-}\left(\mathrm{H}_{2} \mathrm{O}\right)_{\mathrm{n}} \quad(\mathrm{n}=8)$ at the B3LYP/aug-cc-pVTZ level of theory, ordered by increasing relative electronic energy (in $\mathrm{kcal} \mathrm{mol}^{-1}$ ) to the minimum energy isomer at $0 \mathrm{~K}$ and $1 \mathrm{~atm}$. Red text indicates the structure of the interior type geometry. 


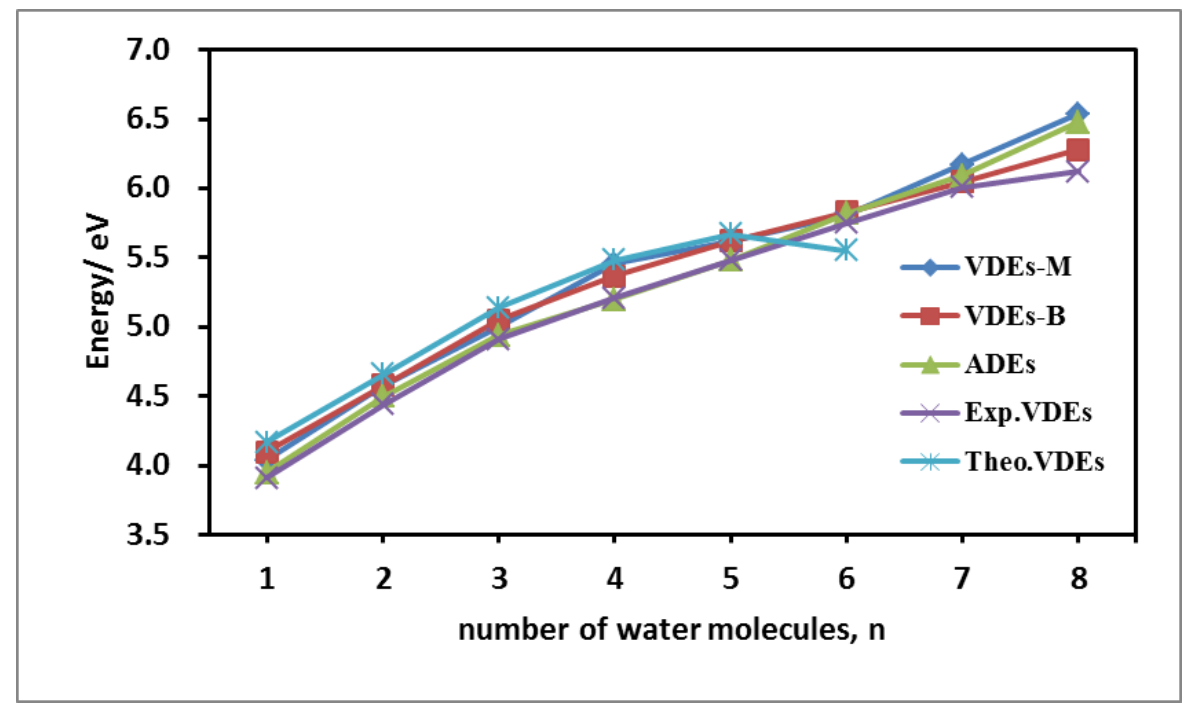

Figure 4 The calculated vertical detachment energies under both MP2/aug-cc-pVDZ (VDEs-M) and B3LYP/aug-cc-pVTZ (VDEs-B) levels of theory, compared with the VDEs experimentally determined by Cheshnovsky (Ref. 5) and the theoretical VDEs previously reported by Neiog et al. (Ref. 25). The calculated adiabatic detachment energies (ADEs) are also included for the $\mathrm{Br}^{-}\left(\mathrm{H}_{2} \mathrm{O}\right)_{\mathrm{n}}, \mathrm{n}=1-8$ clusters. 


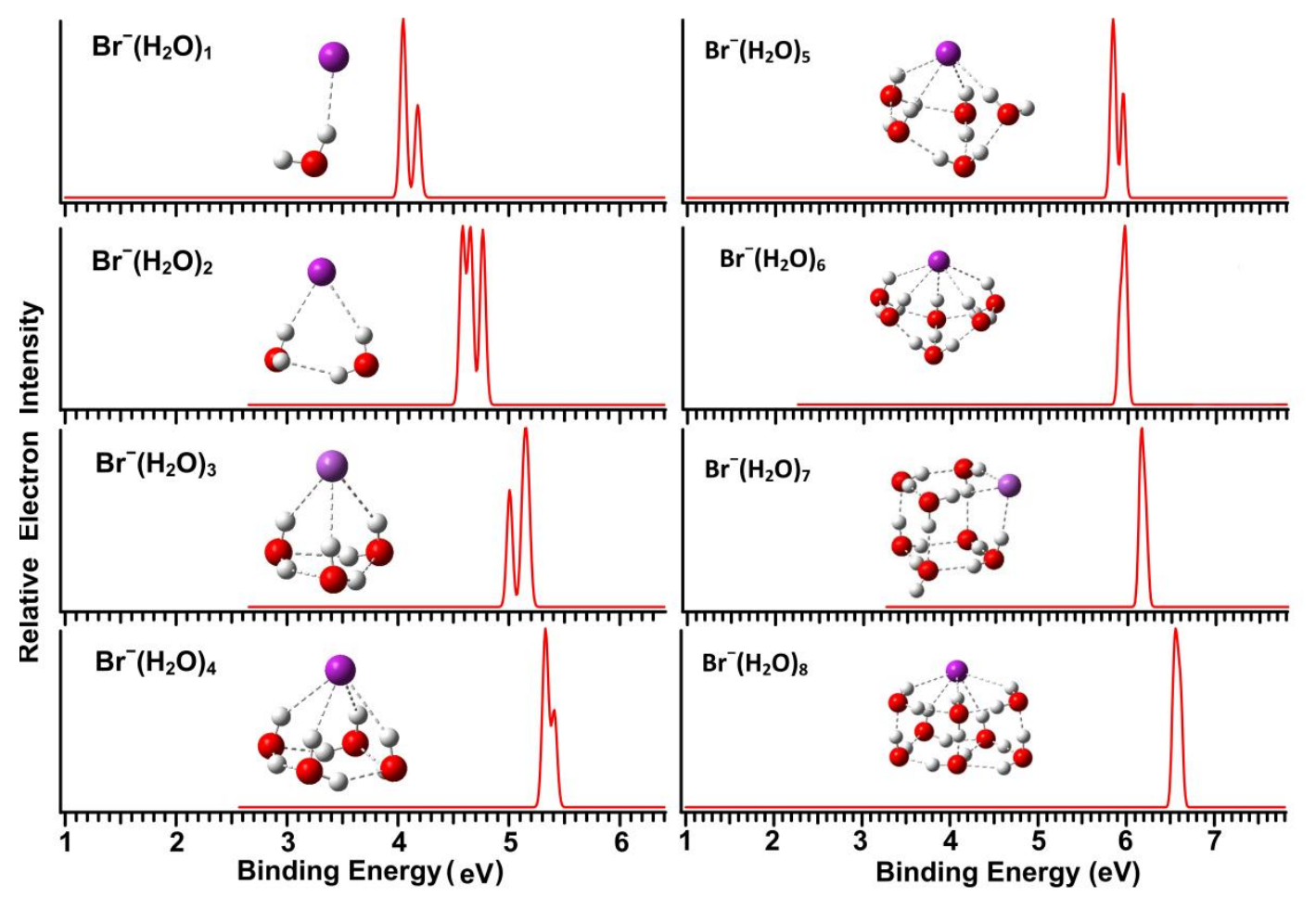

Figure 5 The simulated photoelectron spectra of the minimum energy isomer of $\operatorname{Br}^{-}\left(\mathrm{H}_{2} \mathrm{O}\right)_{\mathrm{n}}, \mathrm{n}=1-8$ clusters at the B3LYP/aug-cc-pVTZ level. The insets show the corresponding structures for each cluster. 


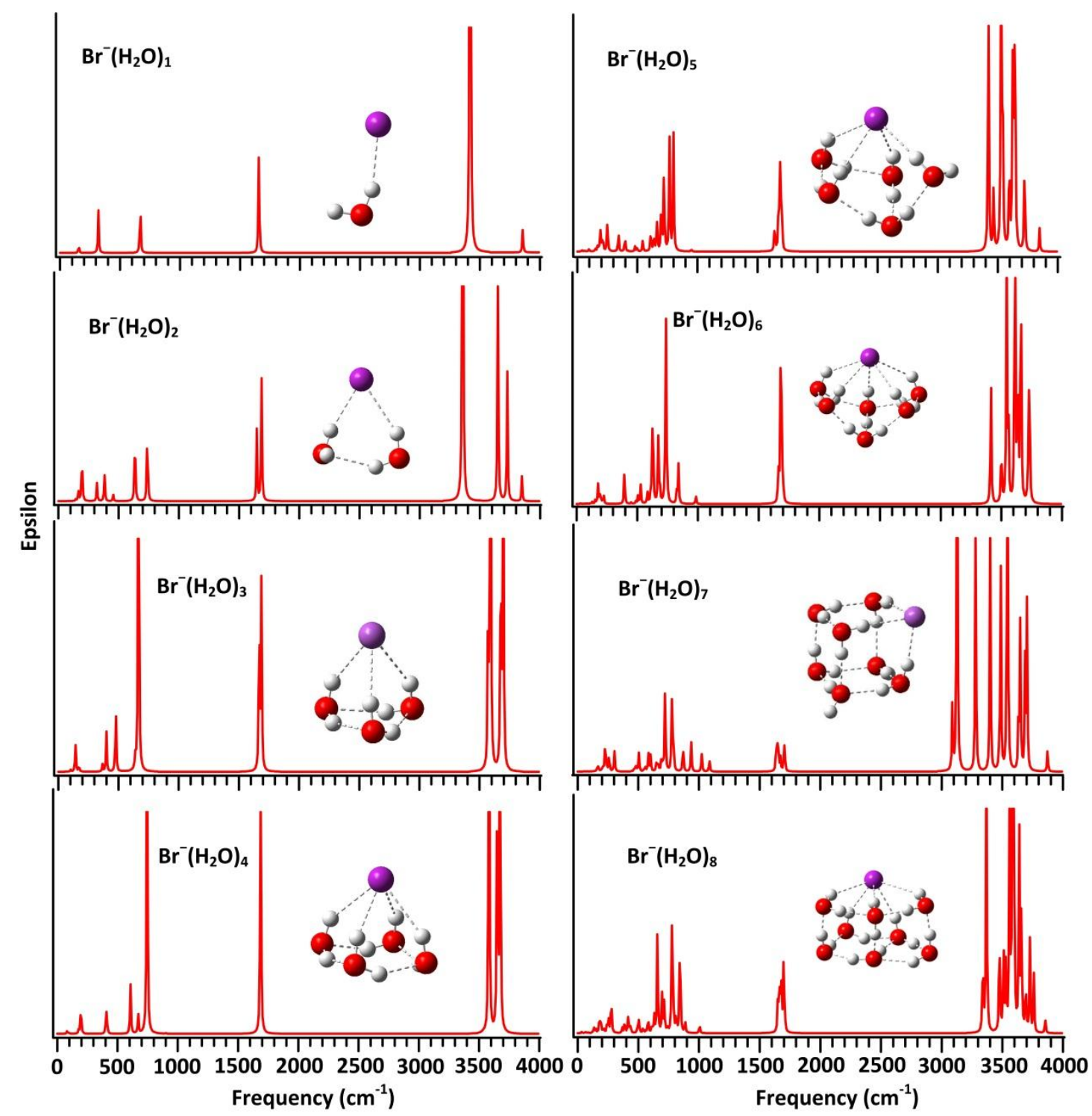

Figure 6 The simulated infrared spectra of the minimum energy isomer of $\operatorname{Br}^{-}\left(\mathrm{H}_{2} \mathrm{O}\right)_{\mathrm{n}}$, $\mathrm{n}=1-8$ clusters at the B3LYP/aug-cc-pVTZ level. The insets show the corresponding structures for each cluster. 

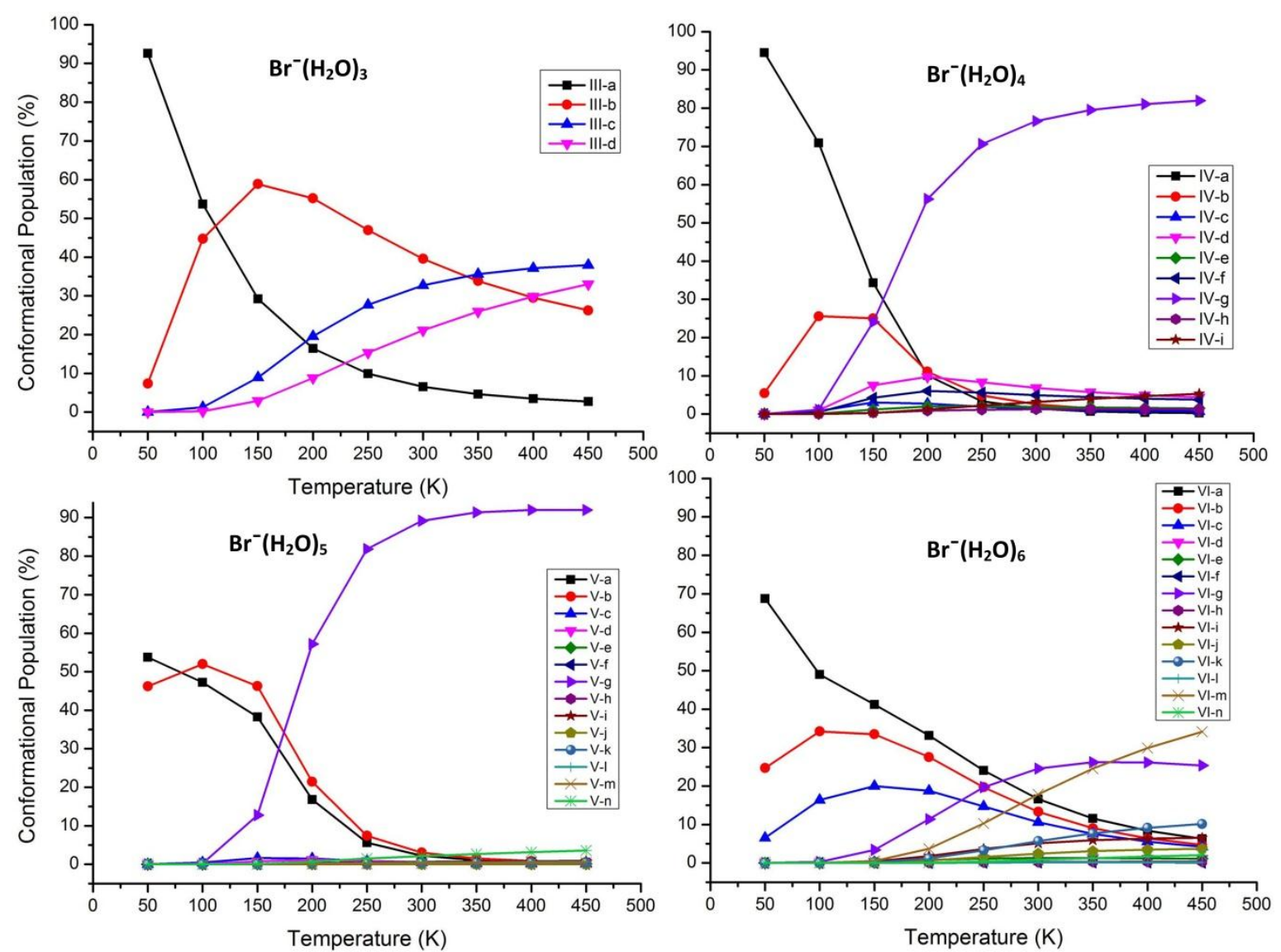

Figure 7 The conformational population change for the low-lying isomers of $\mathrm{Br}^{-}\left(\mathrm{H}_{2} \mathrm{O}\right)_{\mathrm{n}}, \mathrm{n}=3-6$ depending on the temperature variance from $50 \mathrm{~K}$ to $450 \mathrm{~K}$. 

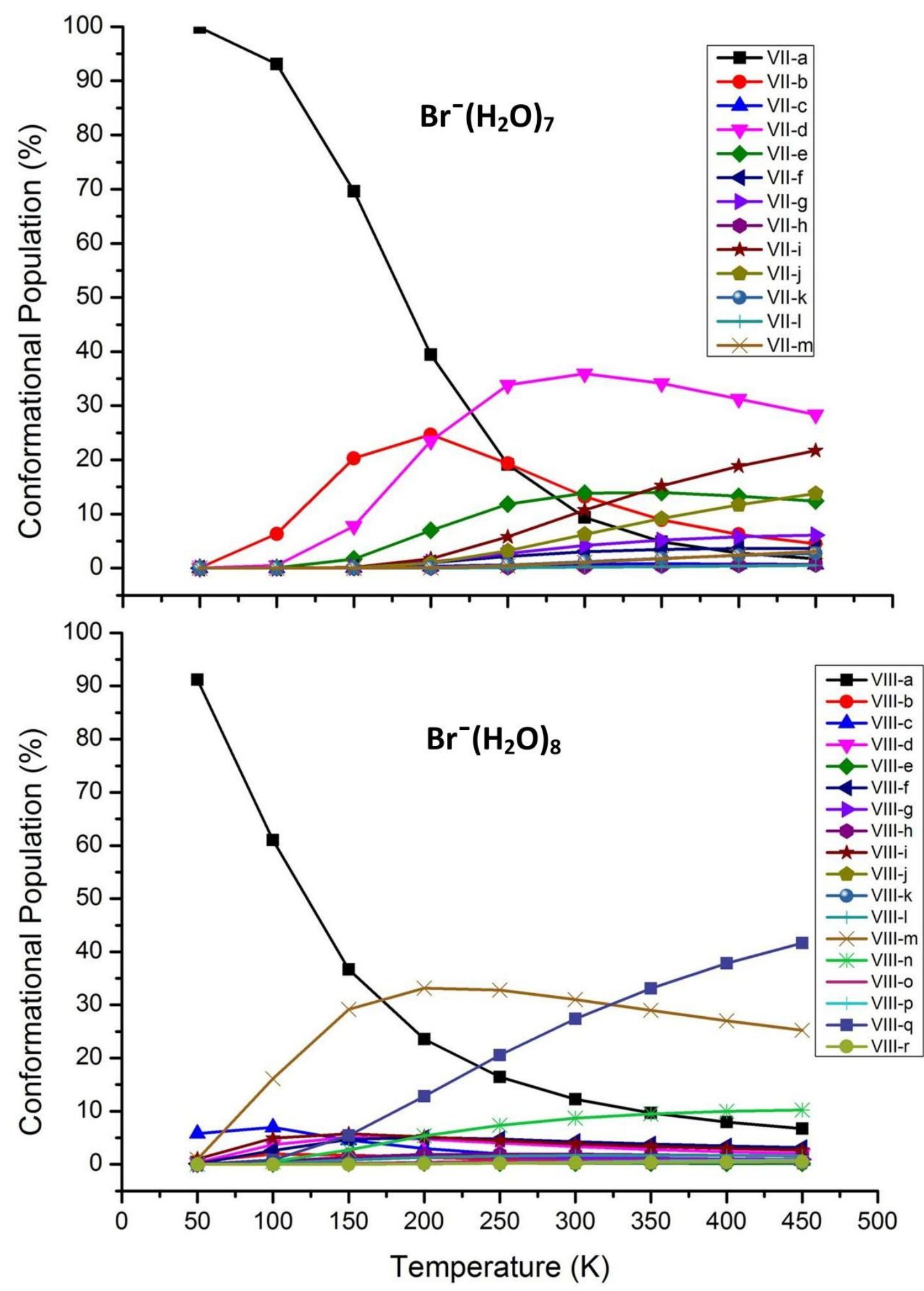

Figure 8 The conformational population change for the low-lying isomers of $\mathrm{Br}^{-}\left(\mathrm{H}_{2} \mathrm{O}\right)_{\mathrm{n}}, \mathrm{n}=7,8$ depending on the temperature variance from $50 \mathrm{~K}$ to $450 \mathrm{~K}$. 


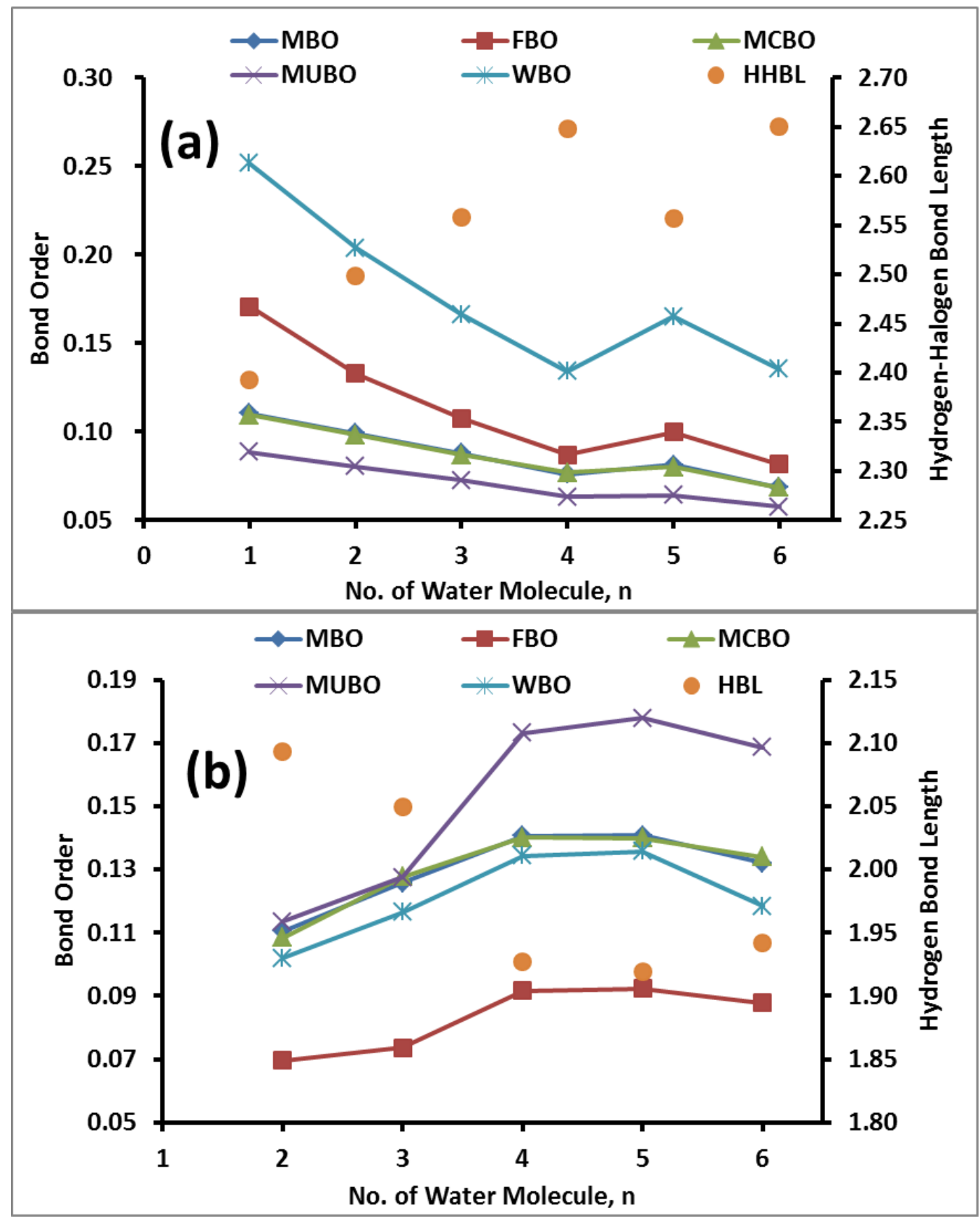

Figure 9. Different bond order analyses: Mayer bond order (MBO), Fuzzy bond order (FBO), Multi-Center bond order (MCBO), and Mulliken bond order (MUBO) of (a) the hydrogen-halogen interaction $\mathrm{O}-\mathrm{H}^{\cdots} \cdot \mathrm{Br}^{-}$and $(\mathrm{b})$ the hydrogen bond $\mathrm{O}-\mathrm{H} \cdots \mathrm{O}$ in different sizes of hydrated bromide clusters, obtained at the B3LYP/cc-pVTZ level of theory. HHBL and HBL stand for the hydrogen-halogen bond length and the hydrogen bond length, respectively. 


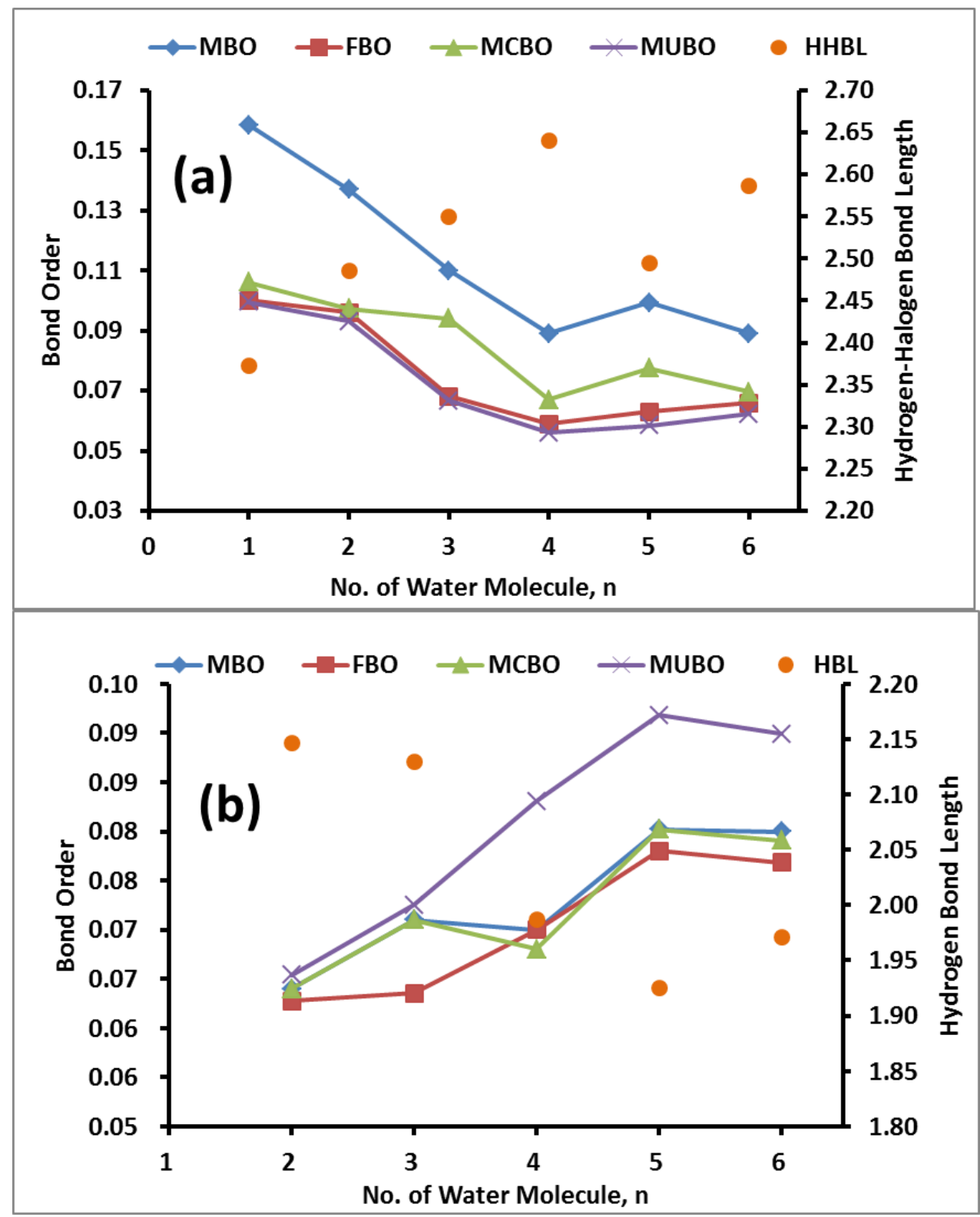

Figure 10. Different bond order analyses: Mayer bond order (MBO), Fuzzy bond order(FBO), Multi-Center bond order (MCBO), Wiberg bond order (WBO), and Mulliken bond order (MUBO) (a) the hydrogen-halogen interaction $\mathrm{O}-\mathrm{H}^{\cdots} \cdot \mathrm{Br}^{-}$and (b) the hydrogen bond $\mathrm{O}-\mathrm{H} \cdots \mathrm{O}$ in different size of hydrated bromide clusters, obtained at the B3LYP/aug-cc-pVTZ level of theory. HHBL and HBL stand for the hydrogen-halogen bond length and the hydrogen bond length, respectively. 